Article

\title{
Improved Photocatalyzed Degradation of Phenol, as a Model Pollutant, over Metal-Impregnated Nanosized $\mathrm{TiO}_{2}$
}

\author{
S. Belekbir ${ }^{1}$, M. El Azzouzi ${ }^{1}$, A. El Hamidi ${ }^{1}$, L. Rodríguez-Lorenzo ${ }^{2}{ }^{\circledR}$, J. Arturo Santaballa ${ }^{3}$ \\ and M. Canle ${ }^{3, *(\mathbb{D}}$ \\ 1 Laboratoire de Physico-Chimie des Matériaux et Nanomateriaux, Faculté des Sciences, \\ Université Mohammed V, Avenue Ibn Battouta, Rabat BP 1014, Morocco; \\ belekbirsoukayna@gmail.com (S.B.); elazzouzim@hotmail.com (M.E.A.); adnane_el@gmail.com (A.E.H.) \\ 2 International Iberian Nanotechnology Laboratory, 4715-330 Braga, Portugal; laura.rodriguez-lorenzo@inl.int \\ 3 Grupo React!, Departamento de Química, Facultade de Ciencias \& CICA, Universidade da Coruña, \\ E-15071 A Coruña, Spain; arturo.santaballa@udc.es \\ * Correspondence: moises.canle@udc.es
}

Received: 7 April 2020; Accepted: 18 May 2020; Published: 22 May 2020

\begin{abstract}
Photocatalyzed degradation of phenol in aqueous solution over surface impregnated $\mathrm{TiO}_{2}(\mathrm{M}=\mathrm{Cu}, \mathrm{Cr}, \mathrm{V})$ under UV-Vis $(366 \mathrm{~nm})$ and UV $(254 \mathrm{~nm})$ irradiation is described. Nanosized photocatalyts were prepared from $\mathrm{TiO}_{2}-\mathrm{P} 25$ by wet impregnation, and characterized by X-ray diffraction, X-ray fluorescence, transmission electron microscopy, UV-Vis diffuse reflectance spectroscopy, Raman spectroscopy, and adsorption studies. No oxide phases of the metal dopants were found, although their presence in the $\mathrm{TiO}_{2}-\mathrm{P} 25$ lattice induces tensile strain in $\mathrm{Cu}$-impregnated $\mathrm{TiO}_{2}-\mathrm{P} 25$, whereas compressive strain in $\mathrm{Cr}$ - and $\mathrm{V}$-impregnated $\mathrm{TiO}_{2}-\mathrm{P} 25$. Experimental evidences support chemical and mechanical stability of the photocatalysts. Type IV $\mathrm{N}_{2}$ adsorption-desorption isotherms, with a small H3 loop near the maximum relative pressure were observed. Metal surface impregnated photocatalysts are mesoporous with a similar surface roughness, and a narrow pore distribution around ca. $25 \AA$. They were chemically stable, showing no metal lixiviation. Their photocatalytic activity was followed by UV-Vis spectroscopy and HPLC-UV. A first order kinetic model appropriately fitted the experimental data. The fastest phenol degradation was obtained with $\mathrm{M}(0.1 \%) / \mathrm{TiO}_{2}-\mathrm{P} 25$, the reactivity order being $\mathrm{Cu}>\mathrm{V}>>\mathrm{Cr}>\mathrm{TiO}_{2}-\mathrm{P} 25$ under $366 \mathrm{~nm}$ irradiation, while $\mathrm{TiO}_{2}-\mathrm{P} 25>\mathrm{Cu}>\mathrm{V}>\mathrm{Cr}$, when using $254 \mathrm{~nm}$ radiation. TOC removal under $366 \mathrm{~nm}$ irradiation for $300 \mathrm{~min}$ showed almost quantitative mineralization for all tested materials, while $254 \mathrm{~nm}$ irradiation for $60 \mathrm{~min}$ led to maximal TOC removal (ca. 30\%). Photoproducts and intermediate photoproducts were identified by HPLC-MS, and appropriate reaction pathways are proposed. The energy efficiency of the process was analysed, showing UV lamps are superior to UVA lamps, and that the efficiency of the surface impregnated catalyst varies in the order $\mathrm{Cu}>\mathrm{V}>\mathrm{Cr}$.
\end{abstract}

Keywords: phenol; photocatalysis; titania; surface impregnation; photodegradation; reaction mechanism; adsorption analysis; energy efficiency

\section{Introduction}

Industry development imply heavy economical charges associated to waste removal, often a cocktail of pollutants harmful to the environment, dangerous for human health, and difficult to degrade by natural mean [1]. Among common persistent pollutants, phenol derivatives are a ubiquitous group. Common sources of phenols pollution in water bodies are paints, pesticides, coal, polymers, food, cosmetic and pharmaceutical industries, resins, oil and petrochemical products. Phenol is cytotoxic, 
damaging the skin and mucous membranes when concentrated, while causing erythema, vesicles and ulcerations, when dilute. It may also cause peripheral neuritis, renal malfunction and liver/kidney necrosis. Moreover, phenol acts as a cardiovascular depressant. General intoxication by phenol may be severe, including possible vascular collapse, respiratory failure and death. Thus, EU directive 80/778/CE has limited phenol concentration in drinking water to $0.5 \mu \mathrm{g} / \mathrm{L}$ [2]. Phenol has been widely accepted as a model persistent organic pollutant in different pollution abatement studies, including photodegradation technologies.

Different methods have been used to achieve phenol safety level, in the range $0.1-1.0 \mathrm{mg} \cdot \mathrm{L}^{-1}[3]$ : adsorption, electrochemical oxidation, biological treatment, etc. However, these processes generate byproducts that may be harmful, making additional treatments necessary, implying further costs [4]. Additionally, these methods cannot give satisfactory yields in terms of pollutant removal because of the solubility of phenol in water. Therefore, it is essential to develop modern technologies for efficient and cheaper treatments [5]. Photocatalysis is one of the most promising methods for complete mineralization of persistent organic pollutants like phenol and derivatives, thus avoiding generation of secondary pollutants $[1,4]$. In brief, photocatalytic degradation of pollutants involves formation of $\mathrm{e}^{-} / \mathrm{h}^{+}$pairs upon irradiation of the semiconductor (SC) with photons of energy higher than or equal to the band gap energy ( $\mathrm{h} v \geq \mathrm{Eg}$ ). An electron is excited from the valence band (VB) to the conduction band $(\mathrm{CB})$ of the $\mathrm{SC}$, yielding an oxidation site $\left(\right.$ hole, $\mathrm{h}^{+}$) and a reduction site (electron, $\mathrm{e}^{-}$). Holes, $\mathrm{h}^{+}$, may oxidize adsorbed organic species, water or $\mathrm{HO}^{-}$, forming strongly oxidant hydroxyl radicals, $\mathrm{HO}{ }^{\bullet}$, or organic radical cations, $\mathrm{R}^{\bullet+}$. Electrons, $\mathrm{e}^{-}$, may reduce $\mathrm{O}_{2}$ to the superoxide radical anion, $\mathrm{O}_{2}{ }^{-}$, or organic species to the corresponding radical anions, $\mathrm{R}^{-}$. Finally, degradation of organic compounds $\mathrm{C}_{\mathrm{x}} \mathrm{H}_{\mathrm{y}} \mathrm{O}_{2}$ into $\mathrm{CO}_{2}$ and $\mathrm{H}_{2} \mathrm{O}$ takes place after reaction with $\mathrm{HO}^{\bullet}, \mathrm{O}_{2}{ }^{--}$, or breakage of $\mathrm{R}^{+}$or $\mathrm{R}^{-}$[6].

A number of SCs have been tested in heterogeneous photocatalysis: $\mathrm{TiO}_{2}, \mathrm{ZnO}, \mathrm{ZnS}, \mathrm{WO}_{3}$, $\mathrm{GaP}, \mathrm{Fe}_{2} \mathrm{O}_{3}, \mathrm{CdS}$, etc. $[7,8]$. The most extensively used photocatalyst is $\mathrm{TiO}_{2}$ which presents many advantages compared to others: it is abundant, inexpensive, stable, efficient and non-toxic [9]. The most effective form of $\mathrm{TiO}_{2}$ for heterogeneous photocatalysis is the commercial titania mixture Evonik $\mathrm{TiO}_{2}-\mathrm{P} 25$. Its very high photocatalytic activity is due to the anatase-rutile junction that reduces the rate of $\mathrm{e}^{-} / \mathrm{h}^{+}$recombination [10]. Despite its excellent photocatalytic performance, it shows a number of drawbacks: (i) it requires excitation wavelengths shorter than $415 \mathrm{~nm}$, as the overlap between sunlight emission and $\mathrm{TiO}_{2}-\mathrm{P} 25$ absorbance is very low, ca. $4 \% \mathrm{UV}$ and (ii) $\mathrm{e}^{-} / \mathrm{h}^{+}$recombination is large, limiting its photoactivity. Other SCs (e.g., $\mathrm{CdS}$ or $\mathrm{GaP}$ ) have advantages such as absorbing larger fraction of sunlight as compared to $\mathrm{TiO}_{2}$, however, they undergo photocorrosion during the photocatalytsis. Different strategies have been developed to improve Vis light absorption and/or to reduce $\mathrm{e}^{-} / \mathrm{h}^{+}$recombination. Among these, doping and impregnation with transition metal ions lead to an improvement in photocatalytic activity [11,12] through the generation of intermediate energy states in the band gap of $\mathrm{TiO}_{2}$ (increasing Vis light absorption) or trapping of photoexcited electrons (reducing $\mathrm{e}^{-} / \mathrm{h}^{+}$recombination) [13]. Photocatalysts have been used for pollution abatement in water, both in suspension and immobilized over suitable supports. Alternative strategies, such as doping $\mathrm{TiO}_{2}$ onto large particles avoid the expensive cost of nanofiltration in real-world environmental applications [14]. Here, we focus on the behavior of suspended photocatalysts, leaving its immobilization for a later stage.

In this study, we have impregnated $\mathrm{TiO}_{2}-\mathrm{P} 25$ with different amounts of metals $(\mathrm{Cu}, \mathrm{Cr}$, and $\mathrm{V})$, to improve visible light harvesting, and investigated the variables controlling phenol photodegradation, as a model of phenolic pollutants abatement, by heterogeneous photocatalysis with the resulting materials under Vis and UV light. $0.1 \%, 0.3 \%, 0.5 \%$, and $1 \%$ of $\mathrm{Cu}, \mathrm{Cr}$, and V were used, and the corresponding reaction mechanism for the phenol photocatalyzed degradation was described. 


\section{Experimental}

\subsection{Materials}

$\mathrm{TiO}_{2}-\mathrm{P} 25$ was purchased from Evonik (ca. 70:30\% anatase: rutile with a small amount of amorphous phase and a surface area of $\left.55 \pm 15 \mathrm{~m}^{2} \cdot \mathrm{g}^{-1}\right)$ [15]. Copper (II) sulfate pentahydrate $\left(\mathrm{CuSO}_{4} 5 \mathrm{H}_{2} \mathrm{O}\right)$ ( $\geq 98 \%$, Sigma), chromium (III) nitrate $\left(\mathrm{Cr}\left(\mathrm{NO}_{3}\right)_{3} \cdot 9 \mathrm{H}_{2} \mathrm{O}(\geq 98 \%\right.$, Sigma), ammonium metavanadate $\mathrm{NH}_{4} \mathrm{VO}_{3}$ (99.996\%, Sigma), and phenol $\left(\mathrm{C}_{6} \mathrm{H}_{5} \mathrm{OH}\right)$ (99.5\% Sigma-Aldrich) were purchased and used without further purification. Acetonitrile was purchased for J.T. Baker with HPLC grade. $\mathrm{O}_{2}$ (purity $\geq$ 99.995\%) gas was used in some experiments. Distilled water used in the experiments was obtained from a Millipore apparatus (Milli-Q water) with a resistivity of $18.2 \mathrm{M} \Omega$ at $298.0 \mathrm{~K}$ and total organic carbon (TOC) less than $5 \mu \mathrm{g} \cdot \mathrm{L}^{-1}$.

\subsection{Catalyst Synthesis}

An incipient wetness impregnation method was adopted for metal immobilization. The desired amount of metal salt was dissolved in distilled water, to which $1 \mathrm{~g}$ of $\mathrm{TiO}_{2}-\mathrm{P} 25$ was added. The mixture was then kept under vigorous stirring at $50{ }^{\circ} \mathrm{C}$ for $24 \mathrm{~h}$. This suspension was dried at $50{ }^{\circ} \mathrm{C}$. Finally, the photocatalysts were calcined at $500{ }^{\circ} \mathrm{C}$ for $4 \mathrm{~h}$ with a ramp rate of $100{ }^{\circ} \mathrm{C} / \mathrm{h}$. The resulting $\mathrm{Cu} / \mathrm{TiO}{ }_{2}$, $\mathrm{Cr} / \mathrm{TiO}_{2}$, and $\mathrm{V} / \mathrm{TiO}_{2}$ photocatalysts were thoroughly ground and labeled as $\mathrm{M}(\mathrm{X} \%) / \mathrm{TiO}_{2}$ where $\mathrm{M}$ stands for the metal and $X$ represents its mass percentage $(0.1 \%, 0.3 \%, 0.5 \%$, and $1 \%)$. To test the stability of the photocatalysts, they were suspended in distilled water for $2 \mathrm{~h}$, with mechanical stirring, and the filtrate composition was analysed for the presence of the corresponding metal cation.

\subsection{Characterization Techniques}

The surface morphology of $\mathrm{TiO}_{2}-\mathrm{P} 25$ and the different $\mathrm{M}(\mathrm{X} \%) / \mathrm{TiO}_{2}$ was recorded using Transmission Electron Microscopy (TEM). The samples were prepared by depositing drops of nanoparticle solutions on carbon formvar coated copper grids (electron microscopy, 200 mesh) and air drying. TEM images were obtained with a Jeol JEM 1100 instrument operating at an acceleration voltage of $80 \mathrm{kV}$ the carbon content was studied by elemental analysis (Thermo Flash 1112). X-ray diffraction (XRD) measurements were carried out on a Bruker Siemens D5000 diffractometer with Bragg-Brentano geometry and $\theta / 2 \theta$ configuration, equipped with a graphite monochromator. The optics consist of $2^{\circ}$ primary and secondary Soller slits, variable output slit, $1 \mathrm{~mm}$ reception slit, $0.2 \mathrm{~mm}$ monochromator slit and $0.6 \mathrm{~mm}$ detector slit. The detector was a scintillation counter. The conditions of acquisition were: sweeping range $(2 \theta): 2-80^{\circ}$, skip size (step size): $0.050^{\circ}$, acquisition time in each jump (time per step) 2.5 s. DiffracPlus v. 8.0.0.2 (Socabim) software was used for data processing.

The anatase mass fraction in the synthesized metal impregnated photocatalysts was calculated from XRD data using the Spurr and Myers Equation (1): [16]

$$
f_{A}=\frac{1}{1+1.265 \frac{I_{R}}{I_{A}}}
$$

where $f_{\mathrm{A}}$ is the mass fraction of crystalline anatase in the $\mathrm{TiO}_{2}-\mathrm{P} 25$ nanoparticles, $I_{\mathrm{R}}$ and $I_{\mathrm{A}}$ are the intensity of the (110) rutile and of the (101) anatase reflection, respectively.

The Scherrer Equation (2): [17]

$$
\tau=\frac{K \cdot \lambda}{\beta \cdot \cos \theta}
$$

was used to calculate the crystallite size $(\tau)$, where $\mathrm{k}$ is a constant $(0.89), \lambda$ is the X-ray wavelength, $\beta$ is the full width at half maximum (FWHM) of the diffraction line and $\theta$ is the diffraction angle. $\theta$ and $\beta$ were taken for $\left(\begin{array}{lll}1 & 0 & 1\end{array}\right)$ and $\left(\begin{array}{lll}1 & 1 & 0\end{array}\right)$ crystal plane of anatase and rutile phase, respectively. The contribution of size and strain to peak broadening was estimated using the Williamson-Hall (W-H) Equation (3): [18] 


$$
\beta_{h k l} \cdot \cos \theta=\frac{K \cdot \lambda}{\tau}+4 \cdot \varepsilon \cdot \sin \theta
$$

where $\varepsilon$ is the microstrain, and also with the size-strain plot (SSP) in accordance with the Equation (4): [19]

$$
\left(d_{h k l} \cdot \beta_{h k l} \cdot \cos \theta\right)^{2}=\frac{K^{\prime}}{\tau} \cdot\left(d_{h k l}^{2} \cdot \beta_{h k l} \cdot \cos \theta\right)+\left(\frac{\varepsilon}{2}\right)^{2}
$$

where $\mathrm{K}^{\prime}$ is a particle shape dependent constant, e.g., 0.75 for spheres.

The composition of the catalyst after its use was tested by semi quantitative $\mathrm{X}$-ray fluorescence on a S4 Pioneer Bruker X-ray spectrofluorometer, equipped with Rh/Ag tube and analyzer crystals LiF200, Ge, PET, OVO-8 and OVO-55. Raman measurements of the dried samples on glass were performed using a Witec Alpha $300 \mathrm{R}$ confocal Raman system equipped with a $633 \mathrm{~nm}$ excitation laser line (10× objective), holographic $600 \mathrm{gr} \cdot \mathrm{mm}^{-1}$ grating and Peltier-cooled CCD detector $\left(-70^{\circ} \mathrm{C}\right)$. Raman spectra were acquired at room temperature over a total spectra range of $90-2800 \mathrm{~cm}^{-1}\left(2.7 \mathrm{~cm}^{-1}\right.$ spectrum resolution) with ten $2 \mathrm{~s}$ accumulations and laser power at the sample of $21 \mathrm{~mW}$. The laser was focused onto the sample by using a 10× objective (N.A. 0.2) providing a laser spot of ca. $3.8 \mu \mathrm{m}$. The Raman band of a silicon wafer at $520 \mathrm{~cm}^{-1}$ was used to calibrate the spectrometer. A simple baseline (as vertical setoff; $y=0$ ) were applied to each spectrum using Spectragryph 1.2.11. The spectra were normalized to the $E_{\mathrm{g}}$ peak $\left(142 \mathrm{~cm}^{-1}\right)$ for a better comparison between samples The positions and widths of the peaks were extracted by fitting the spectrum with pseudo-Voigt functions using Project FOUR ( ${ }^{\circledR}$ 2014, Witec GmbH, Ulm, Germany).

The UV-Vis diffuse reflectance (DRS) spectra $(200-800 \mathrm{~nm})$ of solid photocatalysts were measured on a JASCO V-560 UV-Vis spectrophotometer with a double monochromator and double beam optical system, equipped with an integrating sphere attachment (JASCO ISV-469, Oklahoma City, OK, USA). Reflectance spectra were converted by the instrument software (JASCO) to equivalent absorption Kubelka-Munk units. BET surface areas of the photocatalyst samples were measured using a BET equipment Tristar II Plus (Micromeritics; automatic station with 3 simultaneous measurement ports). The isotherms were measured in the range $P / P_{0}=0.1-1.0$. The gases used were $\mathrm{He}$ (for the measurement of the dead volume of the sample holders) and $\mathrm{N}_{2}$ as adsorption gas. The measurements were made at the temperature of liquid nitrogen $(77.4 \mathrm{~K})$. The BET zone range used for the calculation of the specific surface area was $P / P_{0}=0.05-0.3$. The software used for control, acquisition and data processing was "Microactive for Tristar II Plus", v.2.03 (Micromeritics). To test the stability of the photocatalysts, the filtrate composition was analyzed by ICP-MS (Perkin-Elmer model NexION 300D).

The topography of the metal impregnated photocatalysts was calculated as roughness exponent, also known as fractal dimension $D_{S}$, using the Frenkel-Halsey-Hill Equation (5): [20-23]

$$
\ln S^{l g}=\text { const }-\left(3-D_{S}\right) \cdot \ln \mu
$$

where $S^{l g}$ is the adsorbed amount of nitrogen at the relative pressure $P / P^{0}, D_{S}$ relates to solid roughness and its adsorption and permeability capacity, and $\mu$ is the adsorption potential (Equation (6)):

$$
\mu=R \cdot T \cdot \ln \frac{P^{0}}{P}
$$

\subsection{Photocatalytic Activity}

The photocatalytic activity under UV and near UV-Vis light (NUV-Vis) of the synthesized photocatalysts was tested by monitoring the concentration changes of an aqueous phenol solution $\left(\mathrm{C}_{6} \mathrm{H}_{5} \mathrm{OH}\right)$ in an annular immersion photoreactor (shown schematically in Figure 1). 


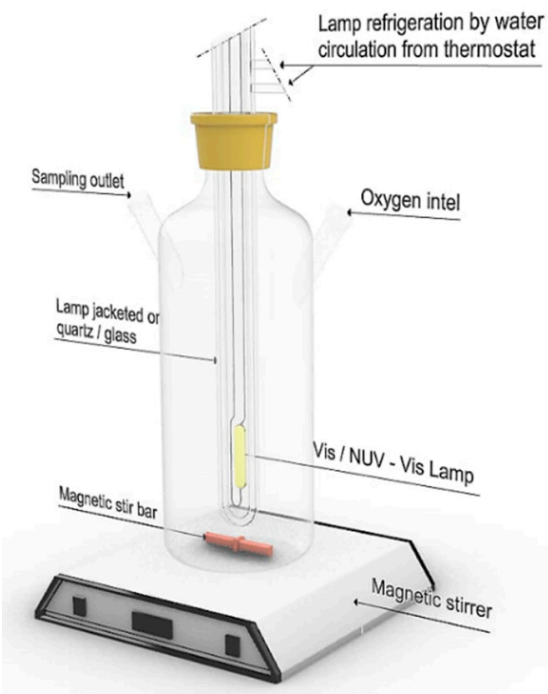

Figure 1. Scheme of the photoreactor used in heterogeneous photocatalysis experiments.

Experiments under NUV-Vis irradiation were carried out with a medium-pressure Hg vapour lamp, with intense emission lines at $\lambda_{\text {exc }}=254,313,366,405,436,546$, and $578 \mathrm{~nm}$. UV lines at $\lambda_{\text {exc }}<366 \mathrm{~nm}$ were filtered using a DURAN $50^{\circledR}$ glass jacket filled with water. The photon flux at $366 \mathrm{~nm}$, as determined by potassium ferrioxalate actinometry [24], was $2.38 \times 10^{-6}$ Einstein. $\mathrm{s}^{-1}$. Experiments under UV irradiation were carried out with a low-pressure Hg vapor lamp, with a single intense emission line at $\lambda_{\text {exc }}=254 \mathrm{~nm}$, located axially in the reactor inside a quartz tube. The photon flux at $254 \mathrm{~nm}$, as determined by potassium ferrioxalate actinometry [24], was of $8.33 \times 10^{-8}$ Einstein. ${ }^{-1}$.

Unless otherwise stated, the different reactions were carried out with $200 \mathrm{~mL}$ of 50 ppm phenol solutions and $200 \mathrm{mg}$ of photocatalyst, in all cases in the presence of $\mathrm{O}_{2}$, under magnetic stirring. The concentration of $\mathrm{O}_{2}$ was routinely tested on the water used, and it was according to the expected solubility at the experimental temperature. All photocatalyst suspensions were allowed to equilibrate in the dark for $30 \mathrm{~min}$ as we know from our previous work that this time is sufficient to allow the establishment of the adsorption-desorption equilibrium [25].

The different heterogeneous suspensions were irradiated for $60 \mathrm{~min}$ under UV light or for $300 \mathrm{~min}$ under NUV-Vis light. Aliquots were withdrawn at given time intervals, and filtered through Sartorius NY $0.45^{\mathrm{TM}}$ filters, for phenol and total organic carbon (TOC) analysis. All kinetic runs were performed at $298.0 \mathrm{~K}$, the temperature being maintained by water flow from a thermostat-cryostat. The $\mathrm{pH}$ of the medium was the natural $\mathrm{pH}$ of the solution, given by the mixture of the photocatalyst and phenol $\left(\mathrm{pH}\left(\mathrm{Cu} / \mathrm{TiO}_{2}\right)=4.7, \mathrm{pH}\left(\mathrm{V} / \mathrm{TiO}_{2}\right)=4.9, \mathrm{pH}(\mathrm{Cr} / \mathrm{TiO} 2)=5.0\right)$.

The photocatalytic degradation efficiency was calculated based on the initial phenol concentration. [Phenol] was monitored by measuring the UV-Vis absorbance at $270 \mathrm{~nm}$, using a Biochrom Libra S70 spectrophotometer, and by UV-Vis HPLC analysis at 210 and $270 \mathrm{~nm}$, in a Thermo Fisher apparatus, equipped with a 6000 LP UV detector, an AS 3000 autosampler and a P4000 solvent pump. A Kromaphase C18 column $(4.6 \mathrm{~mm} \times 150 \mathrm{~mm} \times 5 \mu \mathrm{m})$ was used, with an injected volume of $50 \mu \mathrm{L}$, a flow rate of $1.0 \mathrm{~mL} \cdot \mathrm{min}^{-1}$, at $30{ }^{\circ} \mathrm{C}$, with acetonitrile: water $(25: 75, v / v)$ as mobile phase. The TOC removal efficiency was measured using a ShimadzuTOC-5000A analyzer.

Photoproducts were identified using HPLC/MS (Thermo Scientific LTQ Orbitrap Discovery apparatus), equipped with an electrospray interface operating in negative ion mode (ESI-). A Phenomenex Kinetex XB-C18 column $(100 \mathrm{~mm} \times 2.6 \mu \mathrm{m})$ was used, operated at $30{ }^{\circ} \mathrm{C}$ with elution solvents A ( $0.1 \%$ formic acid) and C (0.1\% methanol.) at flow rate of $200 \mu \mathrm{L} \cdot \mathrm{min}^{-1}$. The gradient was as follows: 0-1 min, 95-95\% A and 5-5\% C; 1-8 $\mathrm{min}, 95-5 \% \mathrm{~A}$ and 5-95\% C; 8-10 $\mathrm{min}, 5-5 \% \mathrm{~A}$ and $95-95 \% \mathrm{C} ; 10-11 \mathrm{~min}, 5-95 \% \mathrm{~A}$ and $95-5 \% \mathrm{C} ; 11-15 \mathrm{~min}, 95-95 \% \mathrm{~A}$ and 5-5\% C. Typical injection 
volumes were 5-25 $\mu \mathrm{L}$. The analyses were carried out using full-scan data dependent MS scanning from $\mathrm{m} / \mathrm{z} 50$ to 500 .

\section{Results and Discussion}

\subsection{Characterization of the Catalysts}

The efficiency of a photocatalyst is related to superficial and structural properties of the semiconductor such as its crystalline structure, surface area, particle size distribution, porosity, band gap, and density of surface hydroxyl moieties [26].

\subsubsection{TEM}

Surface morphologies of $\mathrm{TiO}_{2}-\mathrm{P} 25$ and the different $\mathrm{M}(\mathrm{X} \%) / \mathrm{TiO}_{2}$ were studied using Transmission electron microscopy (TEM). Typical results are shown in Figure 2.
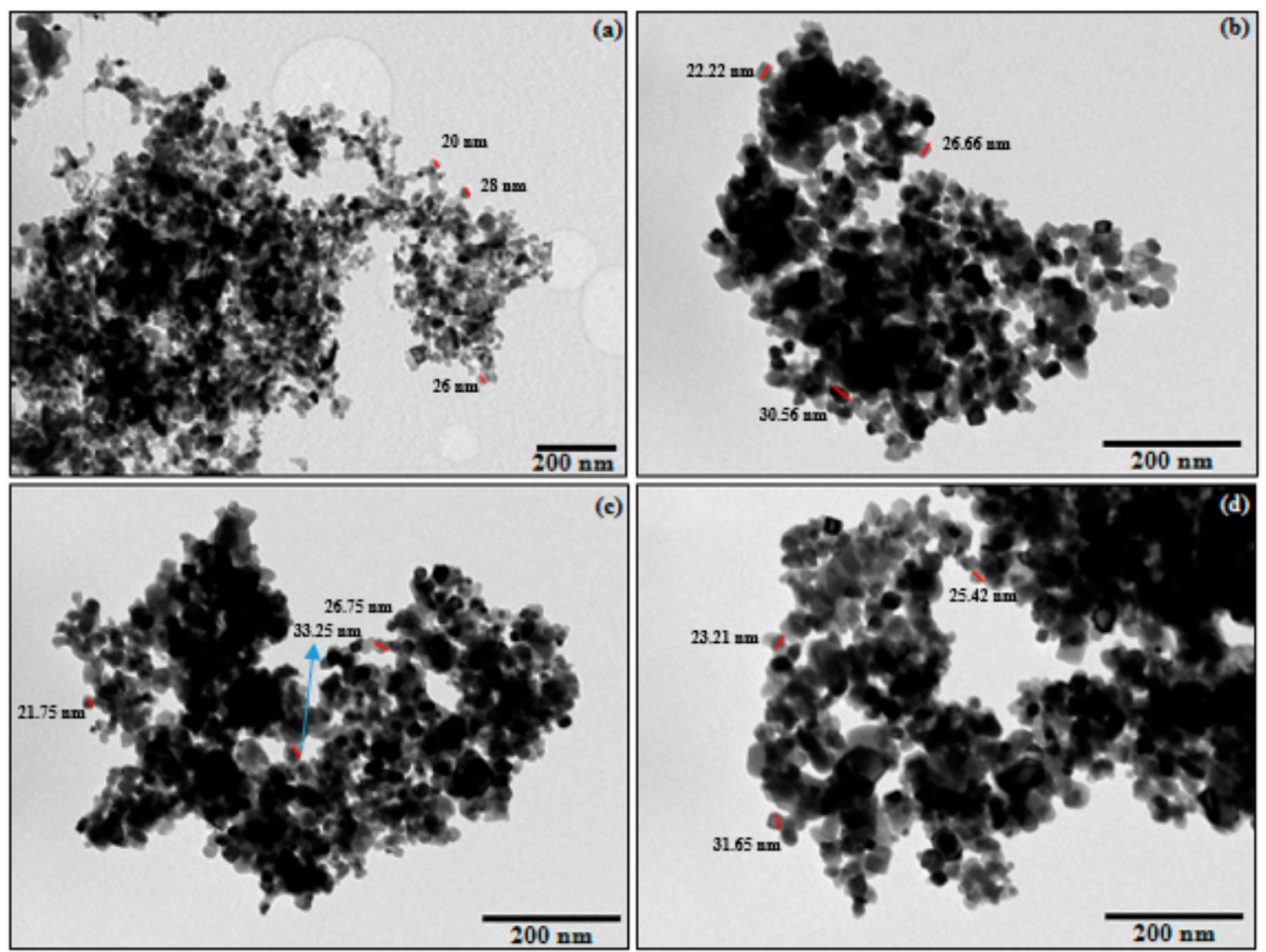

Figure 2. Transmission electron microscopy (TEM) micrographs of (a) $\mathrm{TiO}_{2}-\mathrm{P} 25$, (b) $\mathrm{Cu}(0.1 \%) / \mathrm{TiO}_{2}$, (c) $\mathrm{V}(0.1 \%) / \mathrm{TiO}_{2}$, and (d) $\mathrm{Cr}(0.1 \%) / \mathrm{TiO}_{2}$.

The $\mathrm{TiO}_{2}-\mathrm{P} 25$ sample (Figure 2a) showed mainly homogeneous particles with quite similar morphologies of nanometric size, ranging from 20 to $35 \mathrm{~nm}$. Similar results were observed for $\mathrm{M}(0.1 \%) / \mathrm{TiO}_{2}$ photocatalysts (Figure $2 \mathrm{~b}-\mathrm{d}$ ). Regular shapes were observed in all cases, with similar edges, which is compatible with a common crystalline system, corresponding to the main components of $\mathrm{TiO}_{2}-\mathrm{P} 25$, anatase and rutile, as shown by XRD analysis and Raman spectroscopy (see below). Though the observed crystals appear a bit larger than for the non-impregnated sample, this is not attributed to a crystallite-size effect, as will be discussed below in the XRD section (see below).

Instead, formation of large agglomerates, with sizes between 200 and $600 \mathrm{~nm}$, was observed in all cases, with a higher incidence for $\mathrm{Cu}(0.1 \%) / \mathrm{TiO}_{2}$ as demonstrated qualitatively by scanning 
electron microscopy (SEM) images at low magnification (Figure S1 of Supplementary Information). The homogeneity of the system and the nanometric dimensions play an important role in the photoactivity of a semiconductor catalyst since it influences the electron/hole recombination process [27].

Since the three impregnated photocatalysts do not show relevant morphological changes relative to $\mathrm{TiO}_{2}-\mathrm{P} 25$, similar photocatalytic behavior could be anticipated for them.

\subsubsection{X-ray Diffraction}

The observed X-ray diffraction pattern of $\mathrm{TiO}_{2}$ and $\mathrm{M}(\mathrm{X} \%) / \mathrm{TiO}_{2}$ samples is shown in Figure 3.

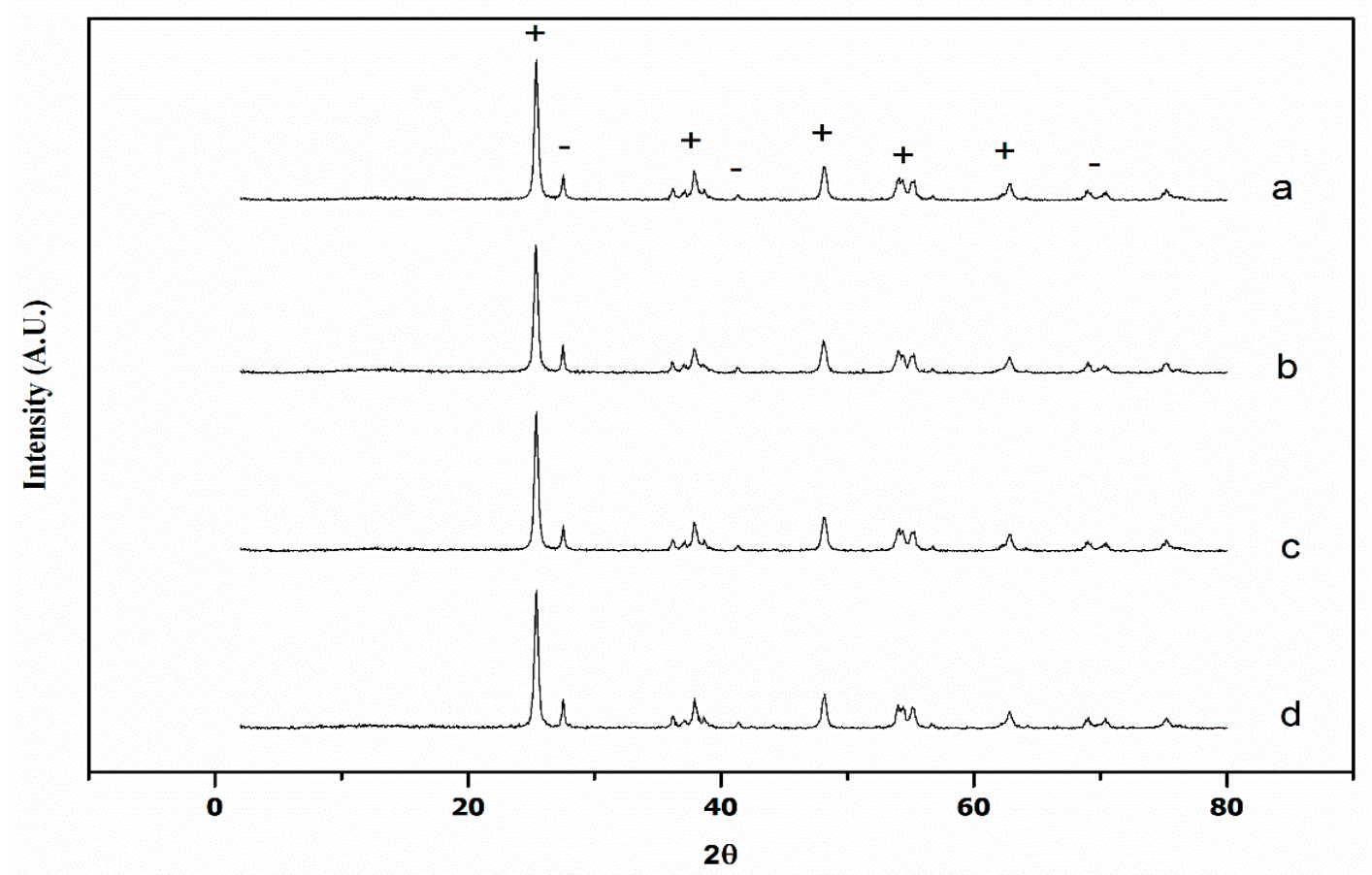

Figure 3. X-ray diffraction patterns of $\mathrm{TiO}_{2}$ and various samples containing $0.1 \%$ of transition metal: (a) $\mathrm{TiO}_{2}-\mathrm{P} 25$, (b) $\mathrm{Cu} / \mathrm{TiO}_{2}$, (c) $\mathrm{V} / \mathrm{TiO}_{2}$, and (d) $\mathrm{Cr} / \mathrm{TiO}{ }_{2}$. + : anatase, -: rutile.

The observed diffraction peaks were assigned to both anatase $\mathrm{TiO}_{2}$ (JCPDS 89-4921), marked ' + ', and rutile $\mathrm{TiO}_{2}$ (JCPDS 65-191) marked ' - '. The corresponding diffraction planes are shown in Table SI01 of the Supporting Information. The diffraction patterns of $\mathrm{Cu}(0.1 \%) / \mathrm{TiO}_{2}-\mathrm{P} 25, \mathrm{Cr}(0.1 \%) / \mathrm{TiO}_{2}-\mathrm{P} 25$ and $\mathrm{V}(0.1 \%) / \mathrm{TiO}_{2}-\mathrm{P} 25$ catalysts were very similar to $\mathrm{TiO}_{2}-\mathrm{P} 25$. These results are typical to the bicrystalline structure of $\mathrm{TiO}_{2}-\mathrm{P} 25$, which is composed of ca. $80 \%$ anatase and $20 \%$ rutile [28], and the rutilization faintly increases in the order $\mathrm{V}>\mathrm{Cr}>\mathrm{Cu}$ (Table 1). The slight shift of diffraction angle suggests a slight lattice distortion relative to non-impregnated $\mathrm{TiO}_{2}-\mathrm{P} 25$ peaks (Table $\mathrm{S} 1$ at the Supporting Information). 
Table 1. Position of selected diffraction peaks, crystallite size $(\tau)$, microstrain $(\varepsilon)$, and anatase mass fraction of $\mathrm{Cu}, \mathrm{Cr}$, and $\mathrm{V}$ surface-impregnated $\mathrm{TiO}_{2}-\mathrm{P} 25$ photocatalysts.

\begin{tabular}{|c|c|c|c|c|c|c|c|}
\hline \multirow[b]{2}{*}{ Phase } & \multirow[b]{2}{*}{$(\mathrm{h} \mathrm{k} \mathrm{l)}$} & \multicolumn{2}{|c|}{$\mathrm{Cu}(0.1 \%) / \mathrm{TiO}_{2}-\mathrm{P} 25$} & \multicolumn{2}{|c|}{$\mathrm{Cr}(0.1 \%) / \mathrm{TiO}_{2}-\mathrm{P} 25$} & \multicolumn{2}{|c|}{$\mathrm{V}(0.1 \%) / \mathrm{TiO}_{2}-\mathrm{P} 25$} \\
\hline & & $2 \Theta / 0$ & $\mathrm{~T}^{\mathrm{a}} / \mathrm{nm}$ & $2 \theta / 0$ & $\mathrm{~T}^{\mathrm{a}} / \mathrm{nm}$ & $2 \theta / 0$ & $\mathrm{~T}^{\mathrm{a}} / \mathrm{nm}$ \\
\hline \multirow{8}{*}{ Anatase } & $\left(\begin{array}{lll}1 & 0 & 1\end{array}\right)$ & 25.399 & 22.4 & 25.362 & 22.4 & 25.404 & 22.4 \\
\hline & $\left(\begin{array}{llll}0 & 0 & 4\end{array}\right)$ & 37.923 & 21.9 & 37.894 & 24.4 & 37.92 & 24.4 \\
\hline & $\left(\begin{array}{lll}2 & 0 & 0\end{array}\right)$ & 48.152 & 17.9 & 48.124 & 23.9 & 48.145 & 21.0 \\
\hline & $(215)$ & 62.834 & 20.0 & 62.824 & 27.1 & 62.819 & 26.3 \\
\hline & \multirow{2}{*}{$\mathrm{W}-\mathrm{H}^{\mathrm{b}}$} & $\tau / \mathrm{nm}$ & 27.4 & \multirow{2}{*}{\multicolumn{2}{|c|}{$-8.0 \times 10^{-4 c}$}} & \multicolumn{2}{|c|}{20.8} \\
\hline & & Strain $(\varepsilon)$ & $8.5 \times 10^{-4}$ & & & \multicolumn{2}{|c|}{$-5.3 \times 10^{-4 c}$} \\
\hline & \multirow{2}{*}{$\mathrm{SSP}^{\mathrm{d}}$} & $\tau / \mathrm{nm}$ & 12.9 & \multirow{2}{*}{\multicolumn{2}{|c|}{0.011}} & \multirow{2}{*}{\multicolumn{2}{|c|}{$05^{c^{12.1}}$}} \\
\hline & & Strain $(\varepsilon)^{\mathrm{c}}$ & 0.011 & & & & \\
\hline \multirow{7}{*}{ Rutile } & $\left(\begin{array}{lll}1 & 0 & 1\end{array}\right)$ & 27.511 & 36.8 & 27.524 & 32.4 & 27.516 & 40.4 \\
\hline & $\left(\begin{array}{lll}1 & 0 & 1\end{array}\right)$ & 36.185 & 30.6 & 36.162 & 39.4 & 36.163 & 31.8 \\
\hline & $\left(\begin{array}{llll}1 & 1 & 1\end{array}\right)$ & 41.134 & 35.0 & 41.305 & 32.3 & 41.387 & 46.7 \\
\hline & \multirow{2}{*}{$\mathrm{W}-\mathrm{H}^{\mathrm{b}}$} & $\tau / \mathrm{nm}$ & 42.8 & \multirow{2}{*}{\multicolumn{2}{|c|}{$\begin{array}{r}31.9 \\
-2.8 \times 10^{-4 c}\end{array}$}} & \multirow{2}{*}{\multicolumn{2}{|c|}{$\begin{array}{r}32.6 \\
-5.5 \times 10^{-4 c}\end{array}$}} \\
\hline & & Strain $(\varepsilon)^{\mathrm{c}}$ & $6.8 \times 10^{-4}$ & & & & \\
\hline & \multirow{2}{*}{$\operatorname{SSP}^{\mathrm{d}}$} & $\tau / \mathrm{nm}$ & 21.4 & \multirow{2}{*}{\multicolumn{2}{|c|}{$-0.006^{c^{16.3}}$}} & \multirow{2}{*}{\multicolumn{2}{|c|}{$-0.004^{c^{c}}$}} \\
\hline & & Strain $(\varepsilon)$ & 0.009 & & & & \\
\hline \multicolumn{3}{|c|}{ Anatase mass fraction $(\%) \mathrm{e}$} & 81.5 & \multicolumn{2}{|c|}{79.4} & \multicolumn{2}{|c|}{78.6} \\
\hline
\end{tabular}

${ }^{a}$ Scherrer equation [17]; ${ }^{b}$ Williamson-Hall equation (W-H) (Figures S2-S4) [18]; ${ }^{c}$ From the negative value of either the W-H equation slope or the size-strain plot (SSP) intercept (Figures S2-S4); ${ }^{\mathrm{d}}$ Size-Strain plot (Figures S5-S7); ${ }^{\mathrm{e}}$ Calculated using Spurr and Myers equation (see Section 2.3) [16].

Only diffraction peaks of the anatase and rutile phases have been found, none belonging to metal oxides, therefore impregnated metals are uniformly distributed on the $\mathrm{TiO}_{2}-\mathrm{P} 25$ surface. It has been reported that only above $65.97 \mathrm{wt} . \% \mathrm{Cu}$ in $\mathrm{TiO}_{2}$ significant cooper oxide peaks can be observed in XRD diffraction patterns [29], whereas full surface coverage is obtained at $>5$ at.\% $\mathrm{Cu}$ [30]. $\mathrm{V}$ incorporates to the lattice at low $\mathrm{V} / \mathrm{Ti}$ ratio and at higher loadings as $\mathrm{V}_{2} \mathrm{O}_{5}$ [31,32]. As observed here, no $\mathrm{Cr}$ phases have been reported for $\mathrm{Cr}(0.001-1 \%) / \mathrm{TiO}_{2}$ (rutile) [33].

Crystallite size values using the Scherrer Equation [17] are listed in Table 1, they are in perfect agreement with TEM observations (see above). Scherrer's crystallite size of the anatase phase is similar for the three photocatalysts ( $c a .22 \mathrm{~nm}), \mathrm{M}(1 \%) / \mathrm{TiO}_{2}-\mathrm{P} 25$. Those values are similar to that reported in the literature, e.g., $\mathrm{V}(0.1 \%)-\mathrm{TiO}_{2}$ (anatase) $[34,35] 28.4 \mathrm{~nm}$. Larger sizes occur for the rutile phase, the order being $\mathrm{V}(0.1 \%) / \mathrm{TiO}_{2}-\mathrm{P} 25>\mathrm{Cu}(0.1 \%) / \mathrm{TiO}_{2}-\mathrm{P} 25>\mathrm{Cr}(0.1 \%) / \mathrm{TiO}_{2}-\mathrm{P} 25$.

XRD peaks broadening is not only due to particle size, strain also plays a role. The simplest model to take size and strain effects into account is the Uniform Deformation Model (UDM), based on the Williamson-Hall equation (see Section 2.3) [18], which assumes that crystals are isotropic. Crystallite sizes obtained using the W-H method (see Table 1) follow the same general trend observed for the Scherrer ones, and are in the same range, again with larger values for the rutile phase.

The very small slopes of the $\mathrm{W}-\mathrm{H}$ equation suggest a high degree of crystallinity, having opposite sign for $\mathrm{Cu}$ and for $\mathrm{Cr}$ - and V-impregnated photocatalysts. From there the corresponding strain $(\varepsilon)$ values have been calculated using the $\mathrm{W}-\mathrm{H}$ equation, see Section 2.3. The positive $\varepsilon$ values, Table 1 , obtained for both phases of $\mathrm{Cu}(0.1 \%) / \mathrm{TiO}_{2}-\mathrm{P} 25$ indicate the presence of tensile strain [36] in this photocatalyst, and, on the contrary, compressive strain occurs in both phases of $\mathrm{V}(0.1 \%) / \mathrm{TiO}_{2}-\mathrm{P} 25$ and $\mathrm{Cr}(0.1 \%) / \mathrm{TiO}_{2}-\mathrm{P} 25$, likely reflecting the effect of the metals ionic radii on the $\mathrm{TiO}_{2}$ lattice. $\mathrm{Cr}^{3+}$ and $\mathrm{V}^{5+}$ ions substitute $\mathrm{Ti}^{4+}$ sites as those ions have similar radii $\left(\mathrm{Ti}^{4+} \approx \mathrm{Cr}^{3+}>\mathrm{V}^{5+}\right.$ ), whereas $\mathrm{Cu}^{2+}$ ions might locate in interstitial positions of the lattice due to its higher size, $0.87 \AA$ vs. $0.745 \AA$ of $\mathrm{Ti}^{4+}$. Crystallite size and strain were calculated using an average SSP method, see Section 2.3. Size, although obviously smaller than those calculated using Scherrer and W-H, shows similar trend to that of W-H 
equation, i.e., larger values obtained for rutile phase. Size differences relative to Scherrer and $\mathrm{W}-\mathrm{H}$ model probably due to the fact that those photocatalysts are non isotropic; here crystallite size was calculated assuming isotropic and spherical crystals, i.e., $\mathrm{K}^{\prime}=\frac{3}{4}$ in the size-strain equation. Tensile strain was found for both phases of $\mathrm{Cu}(0.1 \%) / \mathrm{TiO}_{2}-\mathrm{P} 25$, and compressive strain for both phases of $\mathrm{V}$ and $\mathrm{Cr}$-impregnated photocatalysts, but for anatase phase of $\mathrm{Cr}(0.1 \%) / \mathrm{TiO}_{2}-\mathrm{P} 25$. This result should be taken with precaution, as the isotropy of the crystals is not confirmed.

The XRD of the photocatalysts were also recorded after $2 \mathrm{~h}$ of stirring of photocatalyst suspension in distilled water to check its stability. The obtained XRD patterns are similar to that of $\mathrm{TiO}_{2}-\mathrm{P} 25$, see Table SI01 in the Supporting Information. Minor or no changes have been found in the position of the diffraction peaks, the d-space, the crystallite size and the anatase mass fraction after stirring the photocatalysts suspension in water for two hours (SI01 at the Supporting Information). The filtrate was analyzed by ICP/MS, and the results showed the stability of the photocatalysts, with only traces or ultratraces of the impregnated metals lixiviated after $2 \mathrm{~h}$ stirring: ca. $1 \%$ for $\mathrm{V}$ and $\mathrm{Cr}$, and $<0.02 \%$ for $\mathrm{Cu}$. X-ray fluorescence (XRF) results are in line with this, the semiquantitative analysis of the surface did not show any variation after $2 \mathrm{~h}$ of stirring of the photocatalyst in water. A second and third periods of $2 \mathrm{~h}$ of stirring led only to ultratraces being detected, below the quantification limit of the technique. Similar results were obtained when the photocatalysts were used for photodegradation of phenol in three repeated cycles.

\subsubsection{Raman Spectroscopy}

Figure 4 shows the Raman spectra of $\mathrm{TiO}_{2}$ and $\mathrm{M}(0.1 \%) / \mathrm{TiO}_{2}$ samples. The anatase phase was clearly identified in all the Raman spectra. This phase shows a tetragonal structure with six active Raman modes: $\mathrm{E}_{\mathrm{g}}\left(144,197\right.$, and $\left.639 \mathrm{~cm}^{-1}\right), \mathrm{B}_{1 \mathrm{~g}}\left(399\right.$ and $\left.519 \mathrm{~cm}^{-1}\right)$, and $\mathrm{A}_{1 \mathrm{~g}}\left(519 \mathrm{~cm}^{-1}\right)$.

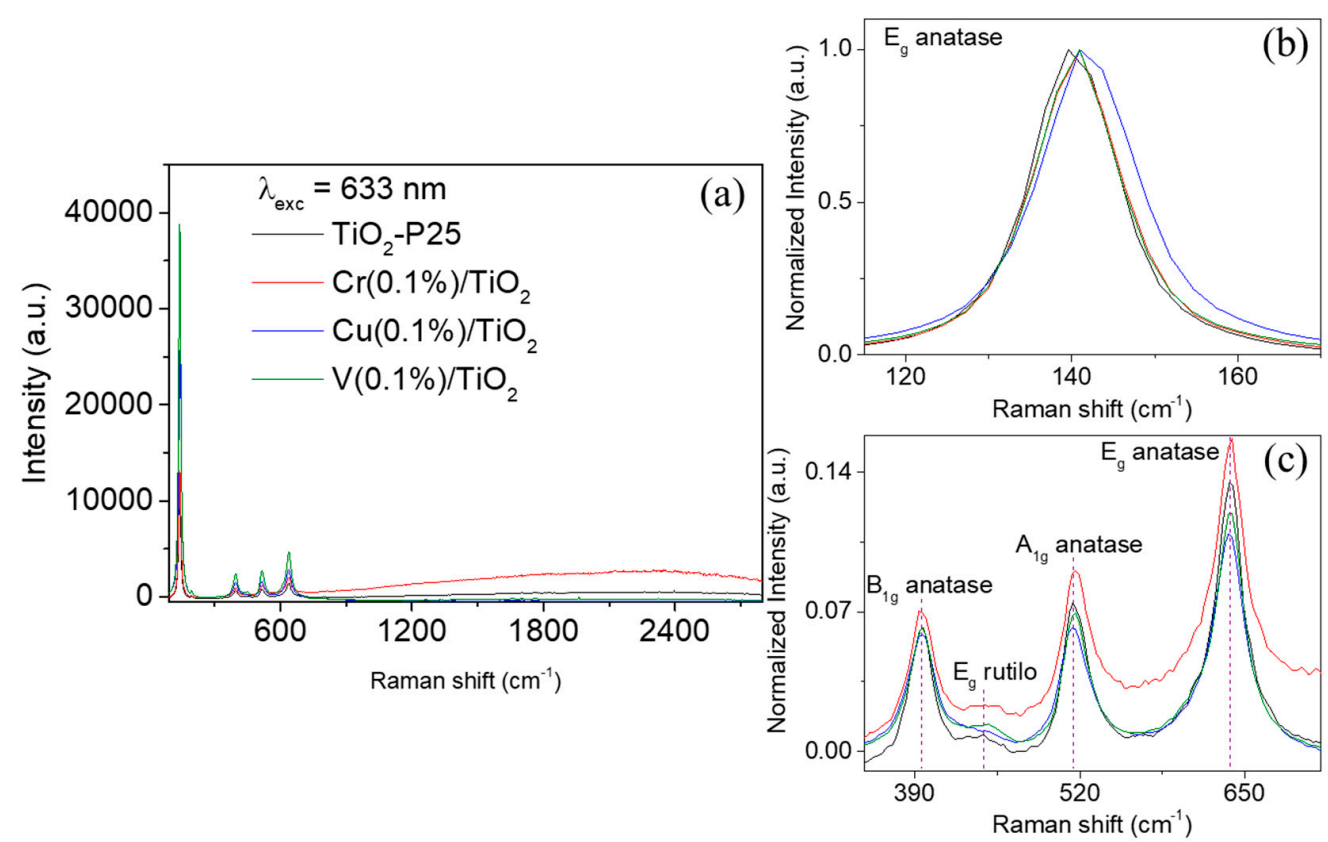

Figure 4. Raman spectra of air-dried non-impregnated $\mathrm{TiO}_{2}$ (black spectrum), $\mathrm{Cr}(0.1 \%) / \mathrm{TiO}_{2}$ (red spectrum), $\mathrm{Cu}(0.1 \%) / \mathrm{TiO}_{2}$ (blue spectrum), and $\mathrm{V}(0.1 \%) / \mathrm{TiO}_{2}$ (green spectrum) sample on glass upon excitation at $633 \mathrm{~nm}$ laser line. (a) Full Raman spectra; (b) expanded spectral window from 110 to $170 \mathrm{~cm}^{-1}$, which a slight red-shift is observed on $\mathrm{E}_{\mathrm{g}}$ Raman mode at impregnated samples. This red-shift is slightly clearer on $\mathrm{Cu}(0.1 \%) / \mathrm{TiO}_{2}$ (blue spectrum). (c) Spectral window from 350 to $710 \mathrm{~cm}^{-1}$, showing that $\mathrm{A}_{1 \mathrm{~g}}$ peak of anatase is slightly shifted and broadened in impregnated samples. Raman spectra shown in (b) and (c) were normalized at maximum intensity of $E_{g}$ Raman band for the sake of comparison. 
In these spectra, a very low-intensity band centred approximately at $455 \mathrm{~cm}^{-1}$ was also observed, which is related with the $\mathrm{E}_{\mathrm{g}}$ mode of the rutile phase, a tetrahedral crystal structure with four active Raman modes: $B_{1 \mathrm{~g}}\left(144 \mathrm{~cm}^{-1}\right), \mathrm{E}_{\mathrm{g}}\left(448 \mathrm{~cm}^{-1}\right), \mathrm{A}_{1 \mathrm{~g}}\left(612 \mathrm{~cm}^{-1}\right)$, and $\mathrm{B}_{2 \mathrm{~g}}\left(827 \mathrm{~cm}^{-1}\right)$ [37]. These five Raman peaks are characteristic of $\mathrm{TiO}_{2}-\mathrm{P} 25$, as a mixture of anatase (80\%) and rutile (20\%) [38]. In the case of $\mathrm{M}(0.1 \%) / \mathrm{TiO}_{2}$ spectra, no extra Raman peak that could be assigned to corresponded metal oxide was observed (i.e., $\mathrm{Cr}_{2} \mathrm{O}_{3}$ at $296\left(\mathrm{E}_{\mathrm{g}}\right), 350\left(\mathrm{E}_{\mathrm{g}}\right), 528\left(\mathrm{E}_{\mathrm{g}}\right), 554\left(\mathrm{~A}_{1 \mathrm{~g}}\right)$, and $615(\mathrm{Eg})$ [39] CuO at 297 $\left(\mathrm{A}_{\mathrm{g}}\right), 344\left(\mathrm{~B}_{\mathrm{g}}\right)$, and $629 \mathrm{~cm}^{-1}\left(\mathrm{~B}_{\mathrm{g}}\right)[40]$, and $\mathrm{V}_{2} \mathrm{O}_{5}$ typically at $285\left(\mathrm{~B}_{2 \mathrm{~g}}\right), 703\left(\mathrm{~B}_{2 \mathrm{~g}}\right)$, and $997 \mathrm{~cm}^{-1}\left(\mathrm{~A}_{\mathrm{g}}\right)[41]$, in agreement with the XRD results (see above sub-Section 3.1.2). This feature indicates that the impregnated metal does not exist as a separate crystalline oxide phase [42].

Figure $4 \mathrm{a}$ shows an increase of the Raman peaks as a function of the nature of the metal cation: $\mathrm{V}>>\mathrm{Cu}>>\mathrm{Cr} \approx$ non-impregnated, which can be attributed to an enhancement of the crystallinity (i.e., total symmetry of the $\mathrm{TiO}_{2}$ molecular structure) of the anatase phase by impregnation mainly with $\mathrm{Cu}$ and $\mathrm{V}$ cations [43]. The spectrum of $\mathrm{Cr}(0.1 \%) / \mathrm{TiO}_{2}$ also showed larger luminescence background than non-impregnated $\mathrm{TiO}_{2}$ sample. The luminescence background disappeared in the case of $\mathrm{Cu}(0.1 \%) / \mathrm{TiO} 2$ and $\mathrm{V}(0.1 \%) / \mathrm{TiO}_{2}$. This optical relaxation, i.e., luminescence, is due to defects in the crystals [44]. Therefore, larger luminescence background in $\mathrm{Cr}$-impregnated sample is due to increased structural distortions of the $\mathrm{TiO}_{2}$ crystal in the presence of $\mathrm{Cr}^{3+}$, which induce weak optical absorption of the $633 \mathrm{~nm}$ laser excitation during the Raman measurements.

Furthermore, a slight red-shift was observed on the $\mathrm{E}_{\mathrm{g}}\left(140 \mathrm{~cm}^{-1}\right)$ peak $\left(\Delta_{\text {Raman-shift }}=2.8-4.4 \mathrm{~cm}^{-1}\right)$ in $\mathrm{M}(0.1 \%) / \mathrm{TiO}_{2}$ samples, being more evident in the case of $\mathrm{Cu}(0.1 \%) / \mathrm{TiO}_{2}$ (Figure $\left.4 \mathrm{~b}\right)$. In the $\mathrm{B}_{1 \mathrm{~g}}$ $\left(512 \mathrm{~cm}^{-1}\right)$ peak was also red-shifted $\left(\Delta_{\text {Raman-shift }}=1.4-3.6 \mathrm{~cm}^{-1}\right)$, but in this case the most important was observed for $\mathrm{Cr}(0.1 \%) / \mathrm{TiO}_{2}$ (Figure $4 \mathrm{c}$ ). It is well-known that substitution of $\mathrm{Ti}^{4+}$ by a dopant with lower oxidation state, $\mathrm{Cu}^{2+}$ or $\mathrm{Cr}^{3+}$ here, causes the generation of oxygen vacancies to conserve local change neutrality within the anatase-lattice. As a consequence of this structural distortion, Raman active peaks of anatase are shifted and broadened [40].

\subsubsection{UV-Vis Diffuse Reflectance Spectroscopy}

The UV-Vis DRS spectra of $\mathrm{Cu}-\mathrm{TiO}_{2}, \mathrm{Cr}-\mathrm{TiO}_{2}$, and $\mathrm{V}-\mathrm{TiO}_{2}$ photocatalysts are displayed in Figure 5. $\mathrm{TiO}_{2}-\mathrm{P} 25$ shows an absorption peak at ca. $300 \mathrm{~nm}$. The absorption band of $\mathrm{TiO}_{2}-\mathrm{P} 25$ from 200 to $400 \mathrm{~nm}$ is ascribed to $\mathrm{O}^{2-}(2 \mathrm{p}) \rightarrow \mathrm{Ti}^{4+}(3 \mathrm{~d})$ transitions in the tetrahedral symmetry [45]. A red shift of the absorption edge is observed for all metal surface-impregnated photocatalysts, although less pronounced for $\mathrm{V}-\mathrm{TiO}_{2}$. The electronic configuration, the energy level, the concentration of the dopants and the applied light intensity play a role in the red shift of the absorption edge into the visible region [46]. Localized states within the band gap and/or oxygen vacancies and radicals associated with the impregnated metals in the $\mathrm{TiO}_{2}-\mathrm{P} 25$ lattice are responsible of the red shift. The different valence states of metal ion dopants relative to $\mathrm{Ti}^{4+}$ is consistent with the generation of oxygen vacancies, giving rise to color centers [47].

Linear extrapolation in the corresponding Tauc plots allows to obtain the band gap $\left(\mathrm{E}_{\mathrm{g}}\right)$ for the different photocatalysts. The corresponding optical bands were typical of semiconductors with an indirect band gap of the allowed transition type $\left(r=2\right.$ for the exponent of the ordinate $(F(R) \cdot h \cdot v)^{1 / r}$ of the insets in Figure 5, and no light emission was observed) [48,49].

The estimated band gap for $\mathrm{P}_{2} 5 \mathrm{TiO}_{2}$ was $3.3 \mathrm{eV}$, in agreement with the value reported in the literature [50,51]. The obtained values are summarized in Table 2, which also show other reported values, sometimes not coincident as they heavily depend on the synthetic method. 

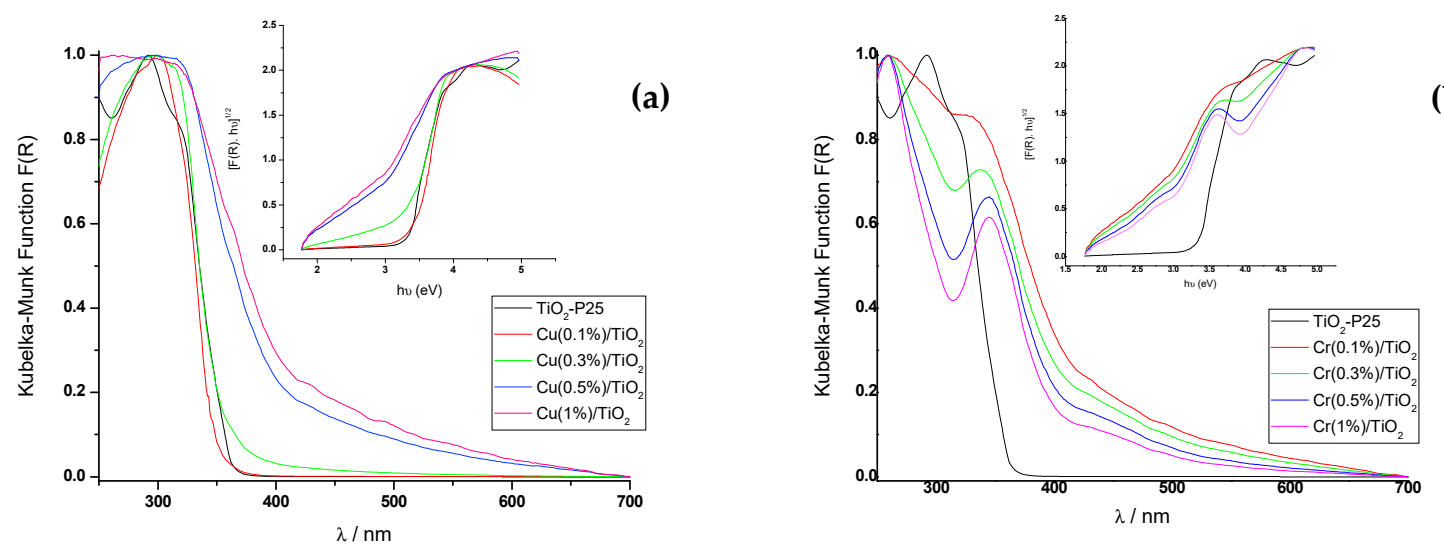

(b)

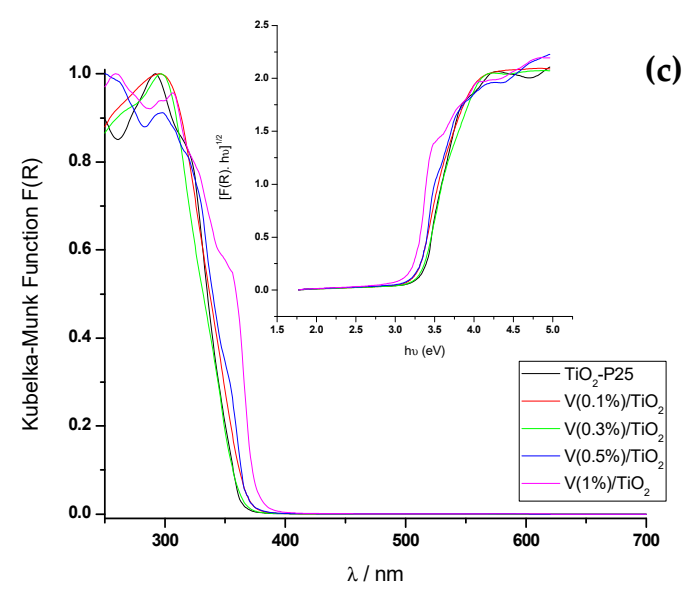

Figure 5. UV-Vis diffuse reflectance (DRS) spectra of $\mathrm{M}(\mathrm{X} \%) / \mathrm{TiO}_{2}$ photocatalysts. $\mathrm{M}$ : (a) $\mathrm{Cu}$, (b) $\mathrm{Cr}$, and (c) V.

Table 2. Band gap values obtained for the metal surface-impregnated $\mathrm{TiO}_{2}$ photocatalysts. The entries in bold were obtained in this work $\left(\mathrm{M}(\mathrm{X} \%) / \mathrm{TiO}_{2}-\mathrm{P} 25\right)$.

\begin{tabular}{cccc}
\hline$\% \mathbf{M} / \mathrm{TiO}_{2}$ & $\mathbf{V}$ & $\mathbf{C r}$ & $\mathbf{C u}$ \\
\hline 0 & $\mathbf{3 . 3 1} ; 3.26[34,35]$ & $\mathbf{3 . 3 1} ; 3.18[23]$ & $\mathbf{3 . 3 0}$ \\
0.02 & $2.92[35]$ & & \\
0.06 & $2.72[35]$ & $3.30 ; 3.16[23]$ & $\mathbf{3 . 2 9}$ \\
0.1 & $\mathbf{3 . 2 6} 2.78[34,35]$ & & $3.0[48]$ \\
\hline 0.2 & & $\mathbf{2 . 0 5}$ & $\mathbf{3 . 5 0}$ \\
\hline 0.3 & $\mathbf{3 . 2 9}$ & $\mathbf{2 . 3 0} ; 3.06[23]$ & $\mathbf{2 . 4 4} ; 3.14[23]$ \\
\hline 0.5 & $\mathbf{3 . 2 6}$ & & $2.72[49]$ \\
\hline 0.88 & & $\mathbf{2 . 4 4}, 3.04[23]$ & $\mathbf{2 . 0 7} ; 3.22[23]$ \\
\hline 1.0 & $\mathbf{3 . 2 1}$ & &
\end{tabular}

The extended absorption of $\mathrm{Cu}$-impregnated $\mathrm{TiO}_{2}-\mathrm{P} 25$ towards the visible region, between 350 and $550 \mathrm{~nm}$, increases with $\mathrm{Cu}$ concentration, such behavior also described in the literature [30], can be assigned to $\mathrm{Cu}^{2+}$ and $\mathrm{Cu}^{+}$oxidation states [51], and attributed to a charge transfer transition from O $2 p$ to d-states of $\mathrm{Cu}$ oxide species, mainly as superficial amorphous $\mathrm{CuO}$-like structure [52-54]. The appearance of this band affected the value of the band gap that decreased drastically to 2.4 and $2.0 \mathrm{eV}$ for $\mathrm{Cu}(0.5 \%) / \mathrm{TiO}_{2}-\mathrm{P} 25$ and $\mathrm{Cu}(1 \%) / \mathrm{TiO}_{2}-\mathrm{P} 25$, respectively (Table 2$)$, which is consistent with 
previous literature reports [55]. Such band gap reduction is due to the d orbitals of $\mathrm{Cu}$, under the $\mathrm{TiO}_{2}$ CB that are able to receive electrons from the $\mathrm{TiO}_{2} \mathrm{VB}$ [56].

Theoretical calculations suggest the band gap narrowing with $\mathrm{Cu}$ content increase due to structure distortions and formation of oxygen vacancies when $\mathrm{Cu}^{2+}$ ions substitute $\mathrm{Ti}^{4+}$ ions. New electronic states in the VB resulting from the covalent interaction between $\mathrm{Cu}$ and $\mathrm{O}$ [40].

The red shift of the absorption edge is also observed to increase with $\mathrm{Cr}$ content in $\mathrm{Cr}$-impregnated $\mathrm{TiO}_{2}-\mathrm{P} 25$ photocatalysts, where both $\mathrm{Cr}^{3+}$ and $\mathrm{Cr}^{4+}$ exist [23], the latter related with heating up to $500^{\circ} \mathrm{C}$ (see Section 2.2). The band observed around $350 \mathrm{~nm}$ becomes more pronounced and shifts to higher wavelength as $\mathrm{Cr}^{3+}$ content increases. It is attributed to ${ }^{4} \mathrm{~A}_{2 \mathrm{~g}} \rightarrow{ }^{4} \mathrm{~T}_{1 \mathrm{~g}}$ of $\mathrm{Cr}^{3+}$ in an octahedral environment; whereas the broad absorption band around 400-700 nm can be assigned to $\mathrm{Cr}^{3+4} \mathrm{~A}_{2 \mathrm{~g}} \rightarrow{ }^{4} \mathrm{~T}_{2 \mathrm{~g}} \mathrm{~d}-\mathrm{d}$ transitions [33,57]. $\mathrm{Cr} / \mathrm{TiO}_{2}-\mathrm{P} 25$ photocatalysts displayed lower band gaps compared to pure $\mathrm{TiO}_{2}-\mathrm{P} 25$ sample [58], the band gap decreases one $\mathrm{eV}$ in going to $\mathrm{TiO}_{2}-\mathrm{P} 25$ to $\mathrm{Cr}(0.5 \%) / \mathrm{TiO}_{2}$, and increases $0.13 \mathrm{eV}$ at $\mathrm{Cr}(1 \%) / \mathrm{TiO}_{2}$ (Table 2).

The small red shift of the absorption edge observed for $\mathrm{V} / \mathrm{TiO}_{2}-\mathrm{P} 25$ also increases with $\mathrm{V}$ content [31], it is the result of the electron transition from the VB $(\mathrm{O} 2 \mathrm{p})$ to the $t_{2 \mathrm{~g}}$ level of $\mathrm{V} 3 \mathrm{~d}$ orbital, located at the bottom of the $\mathrm{TiO}_{2} \mathrm{CB}$ [32]. No noticeable spectral changes were observed in $\mathrm{V} / \mathrm{TiO}_{2}-\mathrm{P} 25$ samples. Hence, the band gap energy was almost constant after impregnation with $\mathrm{V}$ ions (Table 2).

Theoretical calculations suggest band gap reduction in in V and Cr-impregnated P25 is due to the existence of $\mathrm{V}$ and $\mathrm{Cr} 3 \mathrm{~d}$ orbitals between the VB and CB of Cr-doped P25, although in the case of V the $3 \mathrm{~d}$ orbitals are adjacent the conduction band minimum $(\mathrm{CBM})$ so the reduction of $\mathrm{E}_{\mathrm{g}}$ relative to non-impregnated $\mathrm{TiO}_{2}-\mathrm{P} 25$ is lower [59].

\subsubsection{Textural Properties}

$\mathrm{N}_{2}$ adsorption-desorption isotherms of $\mathrm{V}(1 \%) / \mathrm{TiO}_{2}, \mathrm{Cu}(1 \%) / \mathrm{TiO} \mathrm{O}_{2}$, and $\mathrm{Cr}(1 \%) / \mathrm{TiO}_{2}$ photocatalysts (Figure 6, Figures S8 and S9) belong to type IV, according to the IUPAC classification [60], with a small $\mathrm{H} 3$ hysteresis loop, which suggests these photocatalysts are mesoporous. H3 hysteresis loops are typical of mesoporous materials with likely slit-like pores near the maximum relative pressure. The isotherms were used to calculate the specific surface area, using the BET method ( $\mathrm{S}_{\mathrm{BET}}-$ multipoint), and some textural properties based on the Barrett, Joyner, and Halenda (BJH) model [61] (Table 3). $\mathrm{S}_{\mathrm{BET}}$ is similar for the three photocatalysts as well as the monolayer adsorption volume $\left(\mathrm{V}_{\mathrm{m}}\right)$, whereas the BET C constant is similar for $\mathrm{Cu} / \mathrm{TiO}_{2}$ and $\mathrm{Cr} / \mathrm{TiO}{ }_{2}$ photocatalysts and lower for $\mathrm{V} / / \mathrm{TiO}_{2}$, which suggests a weaker interaction between $\mathrm{N}_{2}$ and the photocatalyst. $\mathrm{S}_{\mathrm{BET}}$ values are similar to reported values, e.g., for $\left.\mathrm{Cu}(0.5-10 \%) / \mathrm{TiO}_{2}-\mathrm{P} 25\right) \mathrm{ca} .50 \mathrm{~m}^{2} \cdot \mathrm{g}^{-1}$ [30]. Adsorption below a relative pressure ca. 0.07 fits a monolayer adsorption model. Other than the different BET C constants for $\{\mathrm{Cu}, \mathrm{Cr}\}$ and $\mathrm{V}$ impregnated photocatalysts, the rest of textural properties show similar values. The negative value of the t-plot micropore reinforces the hypothesis of these being mesoporous materials, which is also supported by comparison of their $S_{\mathrm{BET}}$ and $\mathrm{t}$-plot external surface areas (Table 3). Pore size distribution (PSD) was determined from the corresponding isotherms using Barrett, Joyner, and Halenda (BJH) and Dollimore-Heal (D-H) models to calculate differential specific pore volume vs. pore width distribution (Figure 7A and Figure S10). 
Table 3. BET parameters and textural properties of $\mathrm{V}(0.1 \%) / \mathrm{TiO}_{2}, \mathrm{Cu}(0.1 \%) / \mathrm{TiO}_{2}$ and $\mathrm{Cr}(0.1 \%) / \mathrm{TiO}_{2}$ photocatalysts measured by $\mathrm{N}_{2}$ adsorption-desorption. TiO ${ }_{2}-\mathrm{P} 25$ BET surface area $=51\left(\mathrm{~m}^{2} \cdot \mathrm{g}^{-1}\right)[30]$.

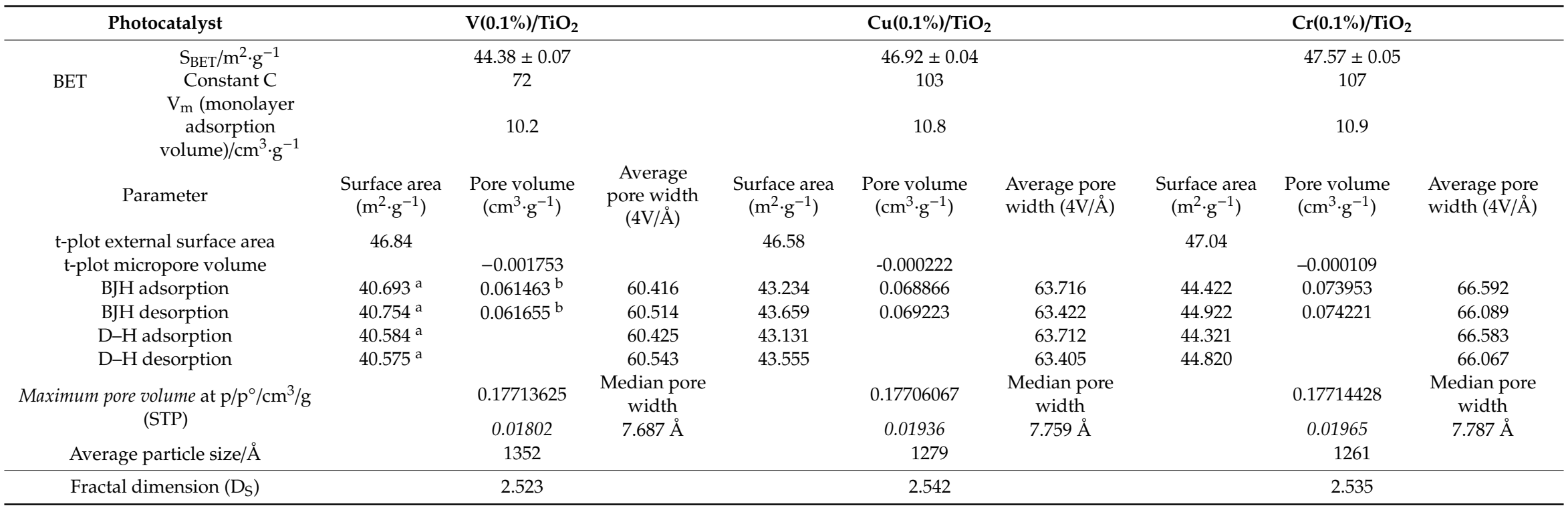

${ }^{a}$ Cumulative surface area of pores between 1.7 and $300 \mathrm{~nm}$ in diameter. ${ }^{b}$ Cumulative pore volume of pores between 1.7 and $300 \mathrm{~nm}$ in diameter. 


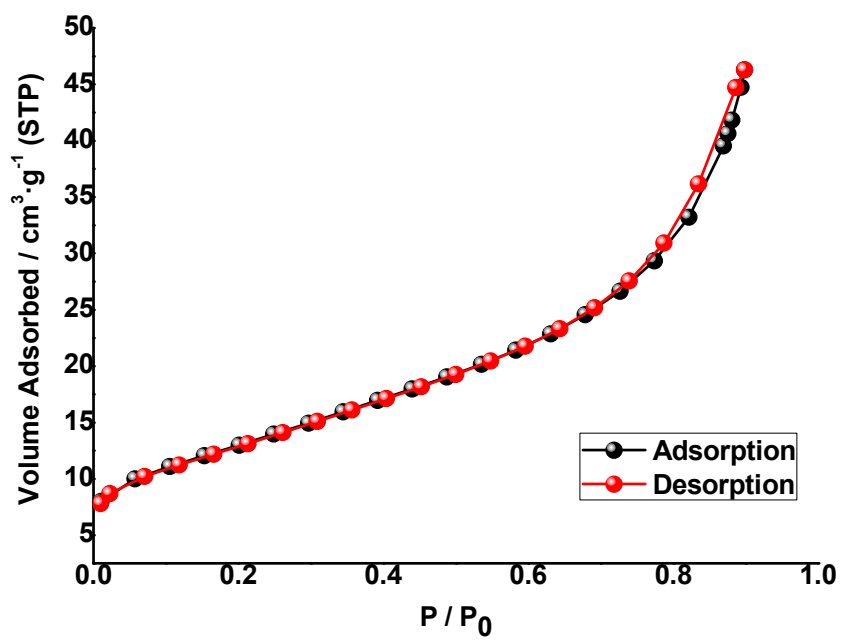

Figure 6. $\mathrm{N}_{2}$ adsorption-desorption isotherm of $\mathrm{Cu}(0.1 \%) / \mathrm{TiO}_{2}$ photocatalyst.
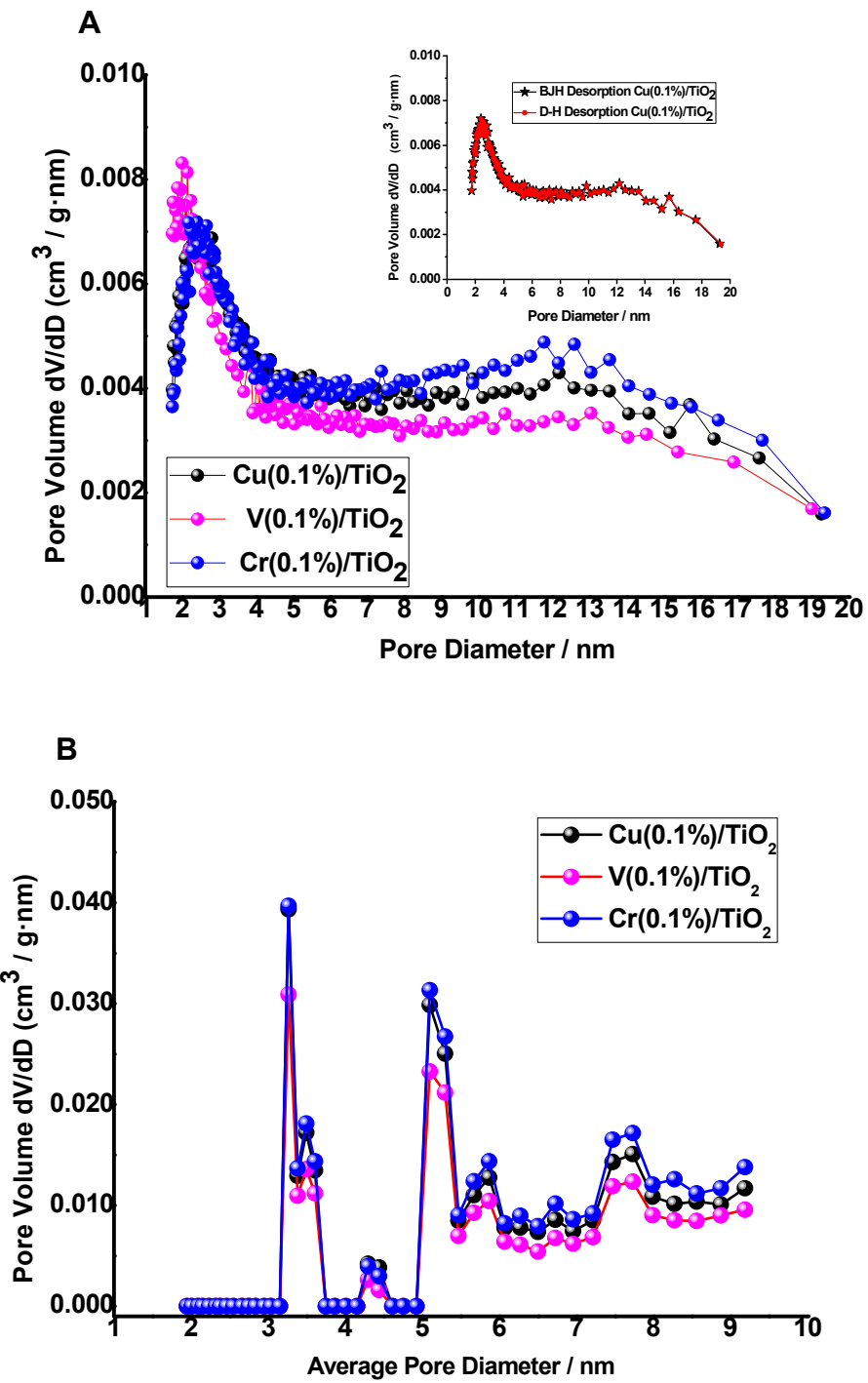

Figure 7. Differential specific pore volume vs. pore width distribution. (A) Barrett, Joyner, and Halenda (BJH) model using desorption branch. Inset: Comparison using BJH and D-H models (desorption). (B) 2D-non-local density functional theory method (NLDFT) model $\left(\mathrm{N}_{2}\right.$-Carbon Finite Pores, Aspect Ratio 6, Standard Slit). 
The three $\mathrm{M}(0.1 \%) / \mathrm{TiO}_{2}$ photocatalysts showed similar results, a narrow PSD centered at ca. $25 \AA$, in the lower limit of mesopores, i.e., $2 \mathrm{~nm}$. BJH and D-H models predict the same PSD as shown in the inset of Figure 7A. It was also observed that PSDs using adsorption and desorption data were fully coincident with BJH and D-H models (Figure S10).

PSDs were also calculated by the non-local density functional theory method (NLDFT) [62]. The 2D-NLDFT model ( $\mathrm{N}_{2}$-Carbon Finite Pores, Aspect Ratio 6, Standard Slit) fitted very well the model isotherms to the experimental ones (Figure S11); the corresponding PSDs for the three impregnated photocatalysts covered a range from 2 to $10 \mathrm{~nm}$ (Figure 7B).

Minor differences have been found in the fractal dimension $\mathrm{D}_{\mathrm{S}}$ (see Section 2.3 and Table 3) between the metal impregnated photocatalysts, $\mathrm{Cu}(0.1 \%) 2.542, \mathrm{Cr}(0.1 \%) 2.535$, and $\mathrm{V}(0.1 \%) 2.523$, respectively, the former showing a slightly higher surface roughness (Figures S12-S14 in the Supporting Information).

\section{Photodegradation of Phenol under Vis and UV Light Irradiation}

The photocatalytic activity of $\mathrm{M}(\mathrm{X} \%) / \mathrm{TiO}_{2}$ samples was tested by monitoring phenol degradation in aqueous solution under NUV-Vis $\left(\lambda_{\text {exc }}>366 \mathrm{~nm}\right)$ and UV $\left(\lambda_{\text {exc }}=254 \mathrm{~nm}\right)$ irradiation. The experimental data were in all cases adequately fit by a first order kinetic model $\left(C=C_{0} \cdot e^{-k \cdot t}\right)$, and the corresponding apparent first order rate constants are collected in Table 4. The rate constants obtained by UV-Vis spectrophotometry and HPLC, with UV detection, are comparable, and the small differences observed follow the same pattern. The effect of impregnation with transition metal ions at different concentrations on phenol removal efficiency is displayed in Figure 8 for $\mathrm{Cu}$, as a prototypical example, and all other effects are shown in Figures S15-S24 in the Supplementary Information.

Table 4. Apparent degradation rate constants obtained in the photocatalyzed degradation of phenol over $\mathrm{M}(\% \mathrm{X}) / \mathrm{TiO}_{2}$ composites under Vis $\left(\lambda_{\mathrm{exc}}>366 \mathrm{~nm}\right)$ and $\mathrm{UV}\left(\lambda_{\mathrm{exc}}=255 \mathrm{~nm}\right)$ irradiation. $[$ Phenol $] 0=50 \mathrm{mg} \cdot \mathrm{L}^{-1},\left[\mathrm{M}(\mathrm{X} \%) / \mathrm{TiO}_{2}\right] 0=1.0 \mathrm{~g} \cdot \mathrm{L}^{-1}$, natural $\mathrm{pH}, \mathrm{T}=298.0 \mathrm{~K}$.

\begin{tabular}{|c|c|c|c|c|c|}
\hline \multirow{2}{*}{$\begin{array}{c}\text { Catalyst } \\
\mathrm{TiO}_{2}-\mathrm{P} 25\end{array}$} & \multicolumn{2}{|c|}{ Detection $^{a} /$ Irradiation $b$} & \multirow{2}{*}{$\frac{\left(\mathbf{k} \pm \sigma_{\mathbf{k}}\right) \cdot 10^{4} / \mathbf{m i n}^{-1}}{\text { HPLC/Vis }}$} & \multirow{2}{*}{\multicolumn{2}{|c|}{$\frac{\left(\mathbf{k} \pm \sigma_{\mathbf{k}}\right) \cdot \mathbf{1 0} \mathbf{4}^{\mathbf{4}} / \mathbf{m i n}^{-\mathbf{1}}}{6.0 \pm 0.2}$}} \\
\hline & HPLC/UV & $765 \pm 96$ & & & \\
\hline \multirow{2}{*}{$\mathrm{M}(\mathrm{X} \%) / \mathrm{TiO}_{2}$} & & \multicolumn{4}{|c|}{$\left(\mathrm{k} \pm \sigma_{\mathrm{k}}\right) \cdot 10^{4} / \mathrm{min}^{-1}$} \\
\hline & & $0.1 \%$ & $0.3 \%$ & $0.5 \%$ & $1.0 \%$ \\
\hline \multirow{4}{*}{$\mathrm{Cu}$} & S/UV & $50 \pm 3$ & $328 \pm 45$ & $80 \pm 6$ & $16 \pm 7$ \\
\hline & HPLC/UV & $58 \pm 4$ & $324 \pm 53$ & $87 \pm 10$ & $21 \pm 2$ \\
\hline & $\mathrm{S} / \mathrm{Vis}$ & $435 \pm 50$ & $252 \pm 40$ & $257 \pm 29$ & $183 \pm 15$ \\
\hline & HPLC/Vis & $493 \pm 51$ & $394 \pm 103$ & $151 \pm 7$ & $140 \pm 8$ \\
\hline \multirow{4}{*}{$\mathrm{V}$} & S/UV & $44 \pm 5$ & $41 \pm 4$ & $35 \pm 2$ & $31 \pm 3$ \\
\hline & HPLC-UV & $50 \pm 5$ & $49 \pm 3$ & $45 \pm 3$ & $36 \pm 3$ \\
\hline & S/Vis & $233 \pm 13$ & $211 \pm 21$ & $89 \pm 4$ & $34 \pm 2$ \\
\hline & HPLC/Vis & $244 \pm 14$ & $193 \pm 13$ & $131 \pm 7$ & $49 \pm 3$ \\
\hline \multirow{4}{*}{$\mathrm{Cr}$} & S/UV & $27 \pm 3$ & $32 \pm 2$ & $52 \pm 4$ & $37 \pm 3$ \\
\hline & HPLC-UV & $24 \pm 3$ & $28 \pm 1$ & $46 \pm 3$ & $35 \pm 2$ \\
\hline & $\mathrm{S} / \mathrm{Vis}$ & $33 \pm 5$ & $25 \pm 3$ & $22 \pm 1$ & $19 \pm 1$ \\
\hline & HPLC/Vis & $34 \pm 5$ & $23 \pm 2$ & $24 \pm 1$ & $21 \pm 1$ \\
\hline
\end{tabular}

Minor or no changes were found in the kinetics and efficiencies of the process upon three repeated cycles of photodegradation using the same batches of photocatalysts.

Phenol photocatalyzed degradation under UV light irradiation is, in general, faster using non-impregnated $\mathrm{TiO}_{2}-\mathrm{P} 25$ (Figure $8 \mathrm{~B}$ and Table 4 ). Though for $0.5 \% \mathrm{Cu}$ the process is faster than for non-impregnated $\mathrm{TiO}_{2}-\mathrm{P} 25$ in the first $30 \mathrm{~min}$, the efficiency of the process with $0.5 \% \mathrm{Cu}$ is lower, not reaching full disappearance of phenol. Similar to previous studies, there is an optimum dopant concentration $[30,54]$, here clearly $0.3 \%$ for $\mathrm{Cu}, 0.1 \%$ for $\mathrm{V}$, and $0.5 \%$ for $\mathrm{Cr}$ (Figure $8 \mathrm{~B}$ and Table 4 ). Limited phenol removal, measured as the loss of absorbance of the reacting mixture at $270 \mathrm{~nm}$, was 
found using metal impregnated $\mathrm{TiO}_{2}-\mathrm{P} 25$ photocatalysts under UV irradiation, usually lower than $30 \%$ (Figure 8B and Figures S19-S24 in the Supplementary Information).

A

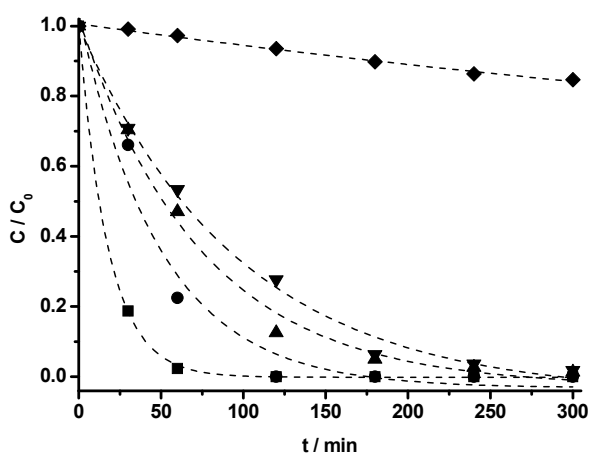

B

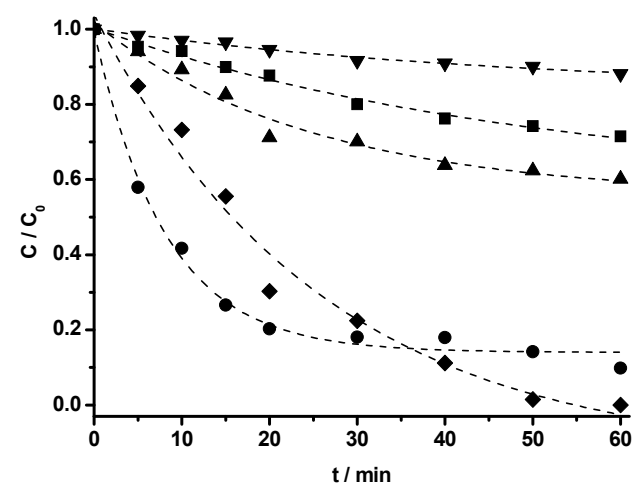

Figure 8. Photodegradation of phenol over $\mathrm{Cu}(\mathrm{X} \%) / \mathrm{TiO}_{2}$ under $(\mathrm{A}) \mathrm{Vis}\left(\lambda_{\mathrm{exc}}>366 \mathrm{~nm}\right)$ irradiation, (B) UV $\left(\lambda_{\mathrm{exc}}=255 \mathrm{~nm}\right)$ irradiation; HPLC-UV detection $(\lambda=270 \mathrm{~nm}) . \mathrm{X} \%$ : $0 \%(\bullet), 0.1 \%(\mathbf{\bullet}), 0.3 \%(\bullet)$, $0.5 \%(\mathbf{\Lambda}), 1 \%(\mathbf{\nabla})$. [Phenol $] 0=50 \mathrm{mg} \cdot \mathrm{L}^{-1},\left[\mathrm{M}(\mathrm{X} \%) / \mathrm{TiO}_{2}\right] 0=1.0 \mathrm{~g} \cdot \mathrm{L}^{-1}$, natural $\mathrm{pH}, \mathrm{T}=298.0 \mathrm{~K}$. Dotted lines show the corresponding first order kinetic fits.

All metal-impregnated photocatalysts showed phenol removals much faster and efficient than the standard $\mathrm{TiO}_{2}-\mathrm{P} 25$ under NUV-Vis light irradiation. Figure 8A shows complete phenol degradation under NUV-Vis light irradiation using $\mathrm{TiO}_{2}-\mathrm{P} 25$ coated with $\mathrm{Cu}$, much faster using $\mathrm{Cu}(0.1 \%) / \mathrm{TiO}_{2}-\mathrm{P} 25$ (half-life ca. $15 \mathrm{~min}$ ) than $\mathrm{Cu}(1 \%) / \mathrm{TiO}_{2}-\mathrm{P} 25$ (half-life ca. $43 \mathrm{~min}$ ). This time the lowest metal content, $0.1 \%$, showed the best result, both in terms of rate and efficiency (understood as reaction extent after $300 \mathrm{~min}$ ). A similar behavior was described in the photocatalyzed degradation of Malachite Green, as here the fastest photodegradation rate was found for non-impregnated $\mathrm{TiO}_{2}$ under UV radiation, whereas it was the slowest under Vis and direct sunlight irradiation. The maximum photodegradation rate was found at $\mathrm{Cu}(1.71 \%)-\mathrm{TiO}_{2}$ [49] under Vis irradiation. A similar behavior was also observed in the NUV-Vis photodegradation of methyl orange, maximum at $\mathrm{Cu}(1 \%)-\mathrm{TiO}_{2}$ [63].

The photocatalytic efficiency for $\mathrm{V} / \mathrm{TiO}_{2}-\mathrm{P} 25$ photocatalysts, under NUV-Vis irradiation, was 99\% (59\%) after $175 \mathrm{~min}$ (300 $\mathrm{min}$ ) for $\mathrm{V}(0.1 \%) / \mathrm{TiO}_{2}-\mathrm{P} 25$ [V(1\%)/ $\left.\mathrm{TiO}_{2}-\mathrm{P} 25\right]$. An optimum dopant concentration has been reported for the degradation of Methylene Blue using $\mathrm{V}$ doped $\mathrm{TiO}_{2}$; [optimum dopant concentration $\left.\mathrm{V}(0.5 \%)-\mathrm{TO}_{2}\right]$ [29], for 4-nitrophenol using $\left[\mathrm{V}(0.5 \%)-\mathrm{TiO}_{2}\right]$ [34], and for 2-4-dichlorophenol [ $\mathrm{V}\left(1 \%\right.$, as $\left.\left.\mathrm{V}^{4+}\right)-\mathrm{TiO}_{2}\right]$ [32].

In the case of $\mathrm{Cr}$, the removal yield reached the highest value of $70 \%$ for $\mathrm{Cr}(0.1 \%) / \mathrm{TiO}_{2}$ after $300 \mathrm{~min}$ under Vis irradiation. The photoactivity of $\mathrm{Cr} / \mathrm{TiO}_{2}-\mathrm{P} 25$ is similar under Vis and NUV irradiation and almost independent of the $\mathrm{Cr}$ content and slightly higher than with bare $\mathrm{TiO}_{2}-\mathrm{P} 25$, such behavior matches that of previously reported [23,64,65].

Here the differences in reactivity do not come from the crystallite size (Table 1) or from the surface roughness (vide supra), they are similar for the three photocatalysts. In addition to crystalline structure and specific surface area, there are other factors playing a relevant role in the photocatalytic activity of metal impregnated photocatalysts; metal dopants might behave as hole $\left(\mathrm{h}^{+}\right)$and/or electron $\left(\mathrm{e}^{-}\right)$traps, therefore changing the electron/pair recombination rate.

The photocatalytic activity of metal impregnated $\mathrm{TiO}_{2}-\mathrm{P} 25$ does not run parallel to the increase of the red-shift of absorption edge and light absorption in the visible light region with dopant concentration. It is well known that beyond an optimum dopant concentration, here $\mathrm{M}(0.1 \%) / \mathrm{TiO}_{2}-\mathrm{P} 25$, the photocatalytic activity decreases [30]. Several reasons can be argued to explain such photoactivity decline after the dopant concentration optimum. First, it might be due to the increase of $\mathrm{e}^{-} / \mathrm{h}^{+}$pair recombination as dopant concentration increases. A higher concentration shortens the distance $(R)$ 
between trap sites of photogenerated $\mathrm{e}^{-} / \mathrm{h}^{+}$pairs and the recombination rate $\left(\mathrm{k}_{\mathrm{RR}}\right)$ of charge carriers increases in accordance with the equation:

$$
k_{R R}=e^{-\frac{2 \cdot R}{a_{0}}}
$$

where $\mathrm{a}_{0}$ is the radius of the hydrogenic wave function for the charge carrier, i.e., metal dopants become recombination centers as the distance between trapping sites shortens [46]. The low photocatalytic effectiveness of $\mathrm{Cr}$-impregnated $\mathrm{TiO}_{2}-\mathrm{P} 25$ likely due to the short diffusion length of the charge carriers (ca. $0.2 \mu \mathrm{m}$ ) [65], leading to a faster $\mathrm{e}^{-} / \mathrm{h}^{+}$recombination rate [32,63].

At the optimum surface impregnation concentration there is an efficient separation between photogenerated $\mathrm{h}^{+}$and $\mathrm{e}^{-}$. The space charge region extends and the surface barrier for recombination is maximum, whereas at higher dopant concentration the space charge region narrows, $\mathrm{e}^{-} / \mathrm{h}^{+}$pairs are produced in the bulk of the photocatalyst, deep trap instead of shallow trap takes place, and volume recombination dominates leading to reduced photocatalytic activity.

Second, a decrease in specific area with concentration means reduction of photoactivity. Third, we hypothesized that the shading effect due to the higher surface coverage as the dopand concentration increases, which also means minor contact area between phenol and $\mathrm{TiO}_{2}-\mathrm{P} 25$ [32]. Fourth, the metal ion can bind to surface hydroxyl groups thus reducing the availability of $-\mathrm{OH}$ groups to be converted into $\mathrm{HO}$ radicals. The increased photocatalytic activity of $\mathrm{Cu}$ and $\mathrm{V}$-impregnated $\mathrm{TiO}_{2}-\mathrm{P} 25$ in the degradation of phenol, under NUV-Vis light irradiation, points to different mechanism of photoactive enhancement under UV and NUV-Vis radiation. In the latter, photoelectrons are transferred from impregnated $\mathrm{TiO}_{2}-\mathrm{P} 25 \mathrm{VB}$ to $\mathrm{Cu}$ or $\mathrm{V} 3 \mathrm{~d}$-orbitals lying just below of the $\mathrm{CB}$, then migrate to form $\mathrm{O}_{2}{ }^{-}$radicals, whereas holes migrate to the surface, react with $\mathrm{HO}^{-}$rendering $\mathrm{HO}$ radicals, then the so-formed radicals are able to initiate the degradation of the adsorbed phenol molecules (Figure 9). Metal ions with charge different than $\mathrm{Ti}^{4+}$ could produce oxygen vacancies in the lattice with energy levels below the $\mathrm{TiO}_{2}-\mathrm{P} 25 \mathrm{CB}$ (Figure 9), allowing visible light harvesting, acting as active sites for adsorbed water dissociation and capturing holes to diminish electron-hole recombination, thus enhancing the photocatalytic activity $[35,66,67]$.

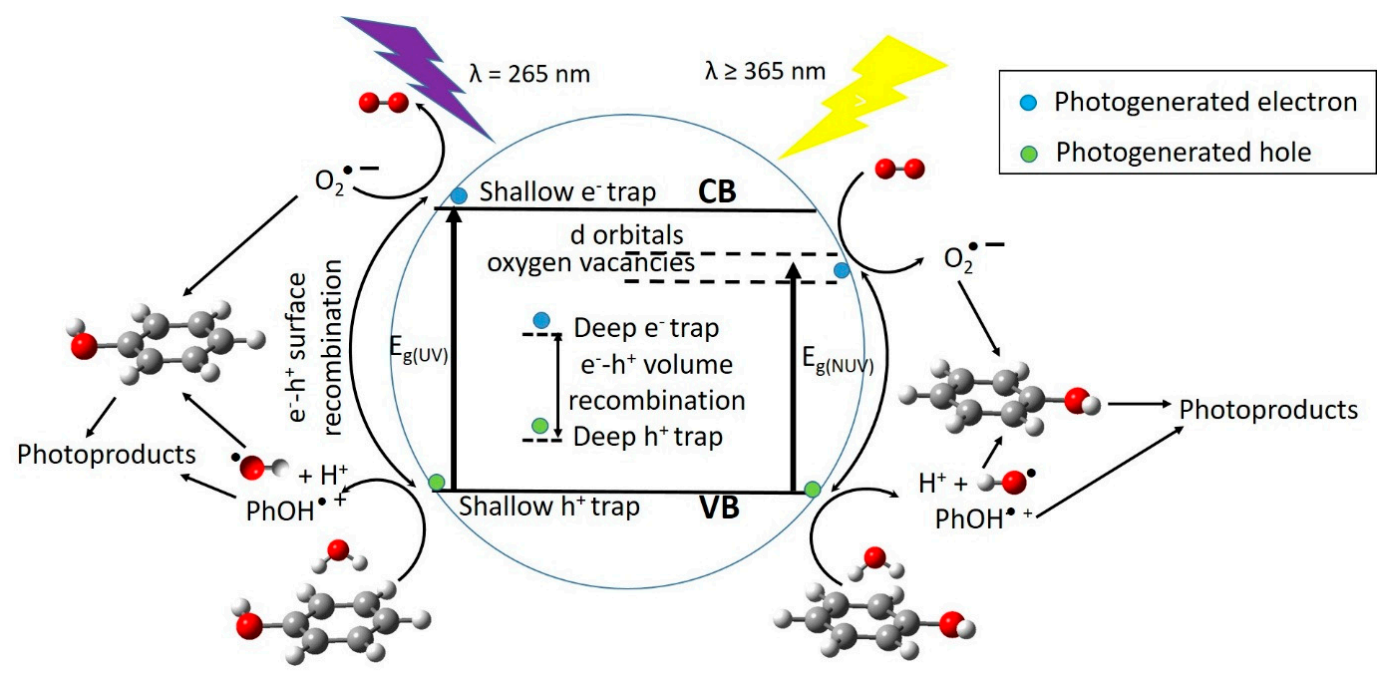

Figure 9. Processes involved in the photocatalyzed degradation of phenol with $\mathrm{M}(\%) / \mathrm{TiO} 2-\mathrm{P} 25$ under UV and near UV-Vis light (NUV-Vis) irradiation.

Photocatalytic activity, among other factors, is not only dependent on the photogenerated charge carriers trapping, efficient detrap to the surface should also occur. Metal dopants can act as $\mathrm{h}^{+}$traps $\left(\mathrm{M}^{\mathrm{n}+}+\mathrm{h}_{\mathrm{VB}}{ }^{+} \rightarrow \mathrm{M}^{(\mathrm{n}+1)+}\right)$ and/or $\mathrm{e}^{-}$traps $\left(\mathrm{M}^{\mathrm{n}+}+\mathrm{e}_{\mathrm{CB}}{ }^{-} \rightarrow \mathrm{M}^{(\mathrm{n}-1)+}\right)$, the energy levels of $\mathrm{M}^{\mathrm{n}+} / \mathrm{M}^{(\mathrm{n}+1)+}$ and $\mathrm{M}^{\mathrm{n}+} / \mathrm{M}^{(\mathrm{n}-1)+}$ lying above $\mathrm{VB}$ and below $\mathrm{CB}$ of $\mathrm{TiO}_{2}-\mathrm{P} 25$, respectively [47]. The stability of $\mathrm{M}^{(\mathrm{n}+1)+}$ and 
$\mathrm{M}^{(\mathrm{n}-1)+}$ depends on the change on the electronic configuration relative to the initial electronic configuration of $\mathrm{M}^{\mathrm{n}+}$, for instance $\mathrm{e}^{-}$trap, better than $\mathrm{h}^{+}$trap should occur for $\mathrm{Cu}^{2+}$, in this way d-orbitals become completely filled. $\mathrm{V}^{5+}$ and $\mathrm{Cr}^{3+}$ should act as hole traps, whereas, for example, it is accepted that $\mathrm{V}^{4+}$ serve both as $\mathrm{h}^{+}$and $\mathrm{e}^{-}$trap [47]. Then $\mathrm{M}^{(\mathrm{n}-1)+}$ can transfer the trapped electron to the $\mathrm{TiO}_{2}-\mathrm{P} 25$ lattice, and from there to adsorbed $\mathrm{O}_{2}$ molecules to yield $\mathrm{O}_{2}{ }^{-}$, or trap a $\mathrm{VB} \mathrm{h}^{+}$turning back to its stable electronic configuration. On the other hand, $\mathrm{M}^{(\mathrm{n}+1)+}$ can transfer its additional positive charge either to adsorbed $\mathrm{HO}^{-}$, forming the reactive $\mathrm{HO}$ radical, or to adsorbed phenol molecules (Figure 9).

In summary, all the studied impregnated photocatalysts were less efficient under UV irradiation (extent of reaction after $60 \mathrm{~min}$ ) than the standard $\mathrm{TiO}_{2}-\mathrm{P} 25$, where photoactivity follows the order: $\mathrm{TiO}_{2}-\mathrm{P} 25>>\mathrm{Cu}>\mathrm{V}>\mathrm{Cr}$, irrespective of the metal percentage in the photocatalyst; whereas under NUV-Vis irradiation, phenol photocatalyzed degradation over $\mathrm{M}(\%) / \mathrm{TiO}_{2}$ composites is faster and more efficient, irrespective of the dopant content, than with $\mathrm{TiO}_{2}-\mathrm{P} 25$, the reactivity order being $\mathrm{Cu}>\mathrm{V}>>\mathrm{Cr}>\mathrm{TiO}_{2}-\mathrm{P} 25$ (extent of reaction after $300 \mathrm{~min}$ ).

\section{Total Organic Carbon}

TOC measurements were carried out to determine the degree of mineralization reached, under both Vis and UV light irradiation. Figure 10 shows the obtained results for the three photocatalysts $(\mathrm{X}=0.1 \%, 0.3 \%, 0.5 \%$, and $1 \%)$ under Vis irradiation. $\mathrm{V} / \mathrm{TiO}_{2}$ was the most efficient photocatalyst for TOC removal, with the maximum removal observed for the lowest metal content $(0.1 \%)$, decreasing as the metal percentage increases, in accordance with kinetic results. On the other hand, $\mathrm{Cr} / \mathrm{TiO}{ }_{2}$ photocatalysts are the less efficient in terms of TOC removal. Comparison between kinetic observations and TOC results suggests that phenol disappearance is faster than mineralization, some organic intermediate photoproducts remain in solution, and the amount depends on the impregnation metal and its concentration. Similar behavior was observed with UV light irradiation (Figure 11), although much lower TOC removals were obtained with the three metal impregnated photocatalysts, which is consistent with kinetic runs (vide supra). The most efficient, in terms of TOC removal, was $\mathrm{Cu}(0.1 \%) / \mathrm{TiO}_{2}$.

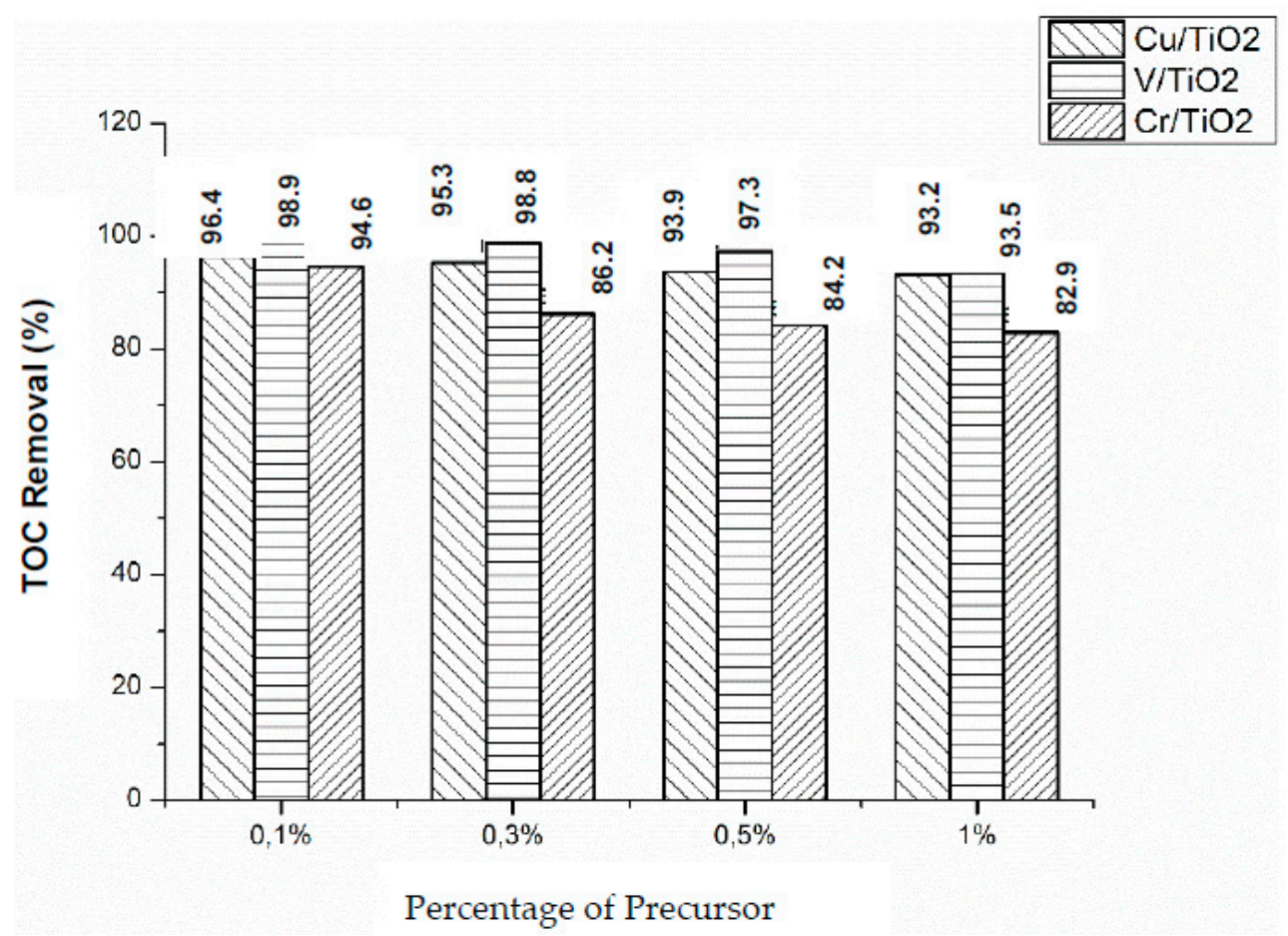

Figure 10. Total organic carbon (TOC) removal during the photocatalytic degradation of phenol over $\mathrm{M}(\mathrm{X} \%) / \mathrm{TiO}_{2}$ after $300 \mathrm{~min}$ of NUV-Vis light irradiation. [Phenol]0 $=50 \mathrm{mg} \cdot \mathrm{L}^{-1},\left[\mathrm{M}(\mathrm{X} \%) / \mathrm{TiO}_{2}\right] 0=$ $1.0 \mathrm{~g} \cdot \mathrm{L}^{-1}$, natural $\mathrm{pH}$, and $\mathrm{T}=298.0 \mathrm{~K}$. 


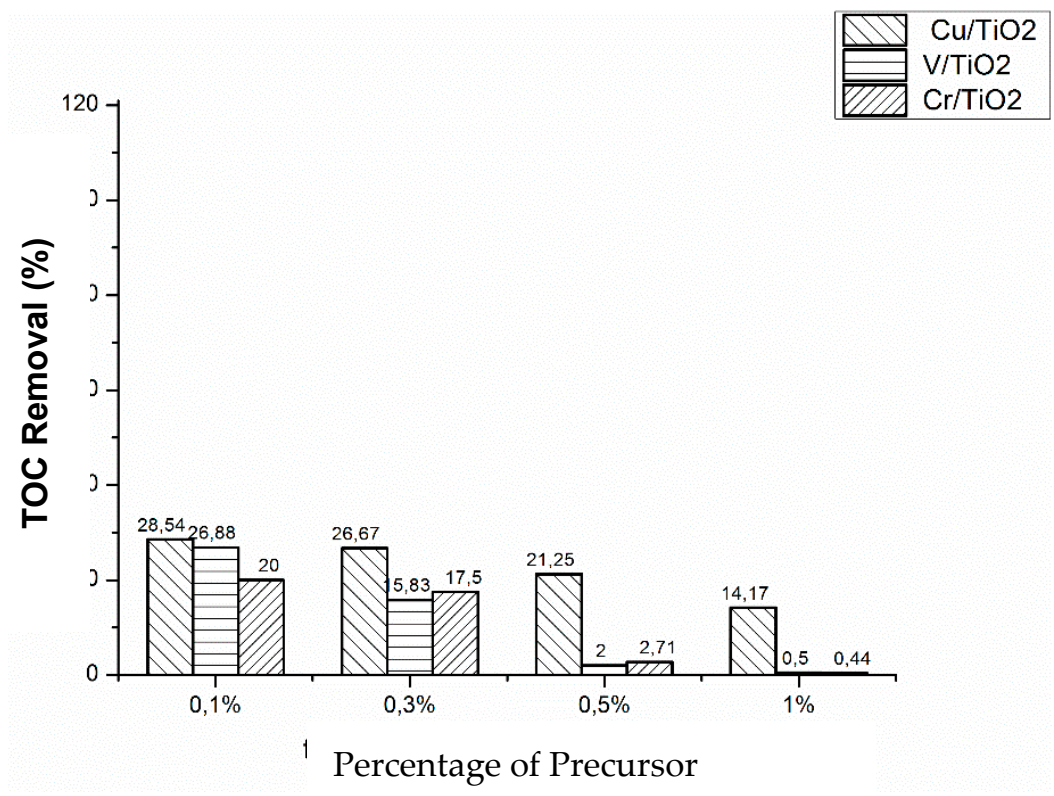

Figure 11. TOC removal during the during photocatalytic degradation of phenol over $\mathrm{M}(\mathrm{X} \%) / \mathrm{TiO}_{2}$ after $60 \mathrm{~min}$ under UV irradiation. [Phenol] $0=50 \mathrm{mg} \cdot \mathrm{L}^{-1},\left[\mathrm{M}(\mathrm{X} \%) / \mathrm{TiO}_{2}\right] 0=1.0 \mathrm{~g} \cdot \mathrm{L}^{-1}$, natural $\mathrm{pH}$, and $\mathrm{T}=298.0 \mathrm{~K}$.

Phenol photocatalyzed degradation over $\mathrm{M} / \mathrm{TiO}_{2}(\mathrm{M}: \mathrm{Cu}, \mathrm{Cr}$, and $\mathrm{V})$, measured either as phenol disappearance or as TOC removal, is higher under NUV-Vis light than under UV irradiation. We have previously found very high efficiencies of NUV-Vis photocatalytic TOC removal using photocatalysts doped with $\mathrm{Cu}$ [25]. Thinking in pollution abatement, although slower, photodegradation is more effective under NUV-Vis, and in economic terms longer time using NUV-Vis radiation counterweight the costs of using UV irradiation sources.

\section{Reaction Pathways for Photocatalyzed Degradation}

Photocatalytic degradation of phenol is a complex multi-stage process. The photocatalytic process with $\mathrm{M}-\mathrm{TiO}_{2}(\mathrm{M}=\mathrm{Cu}, \mathrm{V}$, and $\mathrm{Cr})$ is energetically favourable for the decomposition of phenolic compounds with respect to the process with the standard $\mathrm{TiO}_{2}-\mathrm{P} 25$. Two types of oxidizing species, i.e., the radical hydroxyl $\mathrm{HO}$ and superoxide $\mathrm{O}_{2}{ }^{-}$are involved in the transformation of the aromatic compounds [15]. The lifetime of the intermediates formed at different stages of the reaction is short, as they undergo further fast catalytic oxidation.

We determined the different reaction intermediates using HPLC-MS. Figure 12 shows a typical HPLC chromatogram. The photoproducts found under both UV and Vis light are summarized in Table 5. Identification of the intermediate products is based on the obtained MS and compared to those in databases. The main intermediates identified in this way were: (1) catechol, resorcinol and/or hydroquinone, (2) phloroglucinol, (3) cyclohex-2-ene-1, 2, 4, 5-tetraol, (4) (Z)-penta-2,4-dienoic acid, (5) carbonic acid, (6) (Z)-penta-2,4-dienal, (7) juglone, (8) 9H-xanthen-9-one, (9) 3-hydroxy-2-naphthoic acid, (10) 3-Hydroxy-2-naphthoate, and (11) (2E)-3-(2-formylphenyl) acrylic acid. Degradation pathways into smaller molecules are proposed and also routes leading to heavier transformation products. 


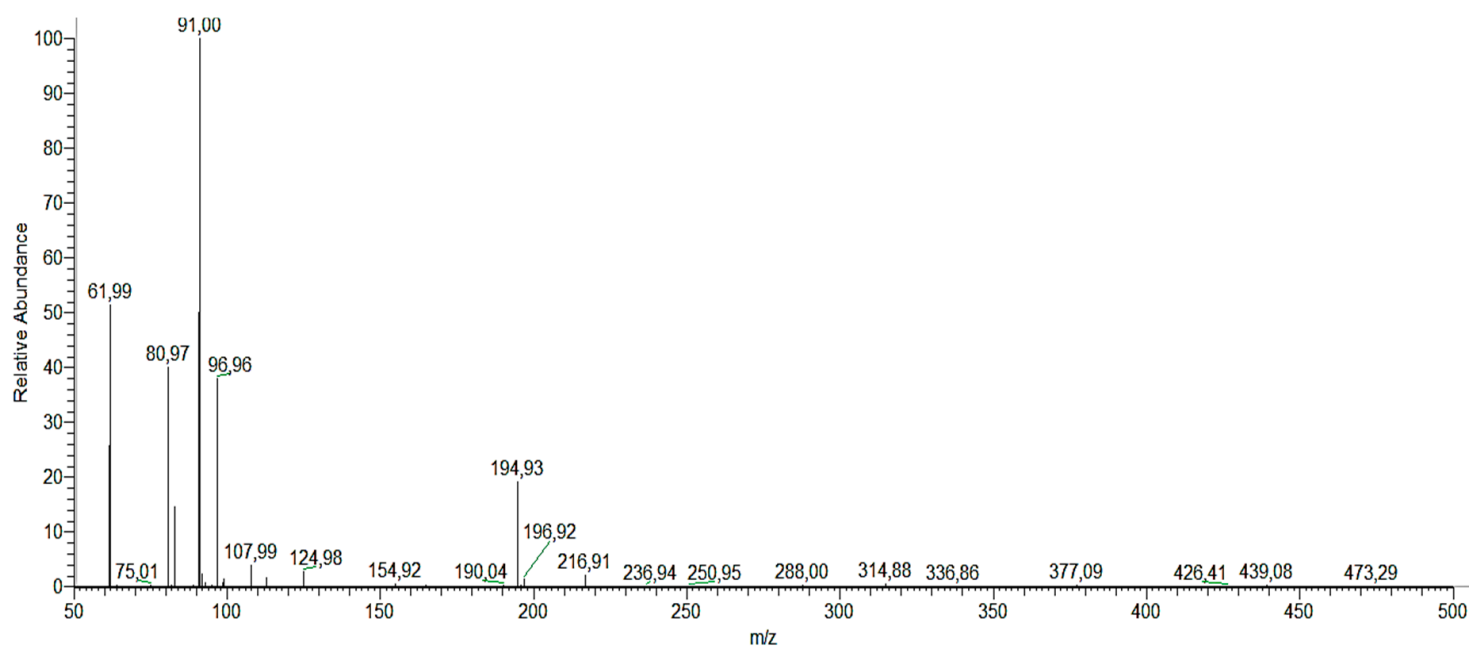

Figure 12. HPLC-MS mass spectra of phenol photoproducts.

Table 5. HPLC-MS data for phenol photoproducts in the photocatalyzed decomposition of phenol over titania-coated metal composites under UV and Vis irradiation.

\begin{tabular}{ccc}
\hline Photoproducts & $\mathbf{( M - H})^{-} \mathbf{( m / z )}$ & $\mathbf{t}_{\mathbf{R}}(\mathbf{m i n})$ \\
\hline (1) catechol, resorcinol and/or & 109.967 & 1.7 \\
hydroquinone & 125.11 & 1.47 \\
(2) phloroglucinol & 145.141 & 5.48 \\
(3) cyclohex-2-ene-1, 2, 4, 5-tetraol & 96.96 & 1.68 \\
(4) (Z)-penta-2,4-dienoic acid & 61.988 & 1.48 \\
(5) carbonic acid & 80.974 & 1.38 \\
(6) (Z)-penta-2,4-dienal & 173.15 & 7.9 \\
(7) juglone & 194.927 & 1.51 \\
(8) (2E)-3-(2-formylphenyl) acrylic acid & 187.101 & 7.9 \\
(9) 3-hydroxy-2-naphthoic acid & 186.172 & 6.95 \\
(10) 3-hydroxy-2-naphthoate & 174.96 & 0.97 \\
(11) 9H-xanthen-9-one & &
\end{tabular}

Phenol photocatalyzed degradation over titania-coated metal composites under UV and Vis light irradiation is described by the reaction mechanism shown in Figure 13. Photocatalyzed phenol degradation proceeds through the widely accepted mechanisms of electrophilic attack promoted by $\mathrm{HO}$ or $\mathrm{h}^{+}$oxidation of the adsorbed phenol onto the photocatalyst surface [66]. Though a deep understanding of the surface processes taking place is out of the scope of this article, in support to the previous statement, we have observed that the presence of iso-Propanol as HO scavenger or EDTA as $\mathrm{h}^{+}$scavengers inhibit the process largely or completely.

Phenol oxidation occurs by hydroxylation to yield dihydroxylbenzenes (1) (catechol, resorcinol, and/or hydroquinone) $[67,68]$. Further hydroxylation produces phloroglucinol (2) and likely other trihydroxybenzenes. The hydroxylation of the former with addition of hydrogen gives (3) which leads to intermediates (4) and (5) by ring opening via $\mathrm{C}-\mathrm{C}$ bond breaking, then dehydroxylation of (4) and hydrogen addition leads to (6). Several radical species are formed in phenol photodegradation [69-72] that can react between them to give the other intermediates (7-11) found in this work. 


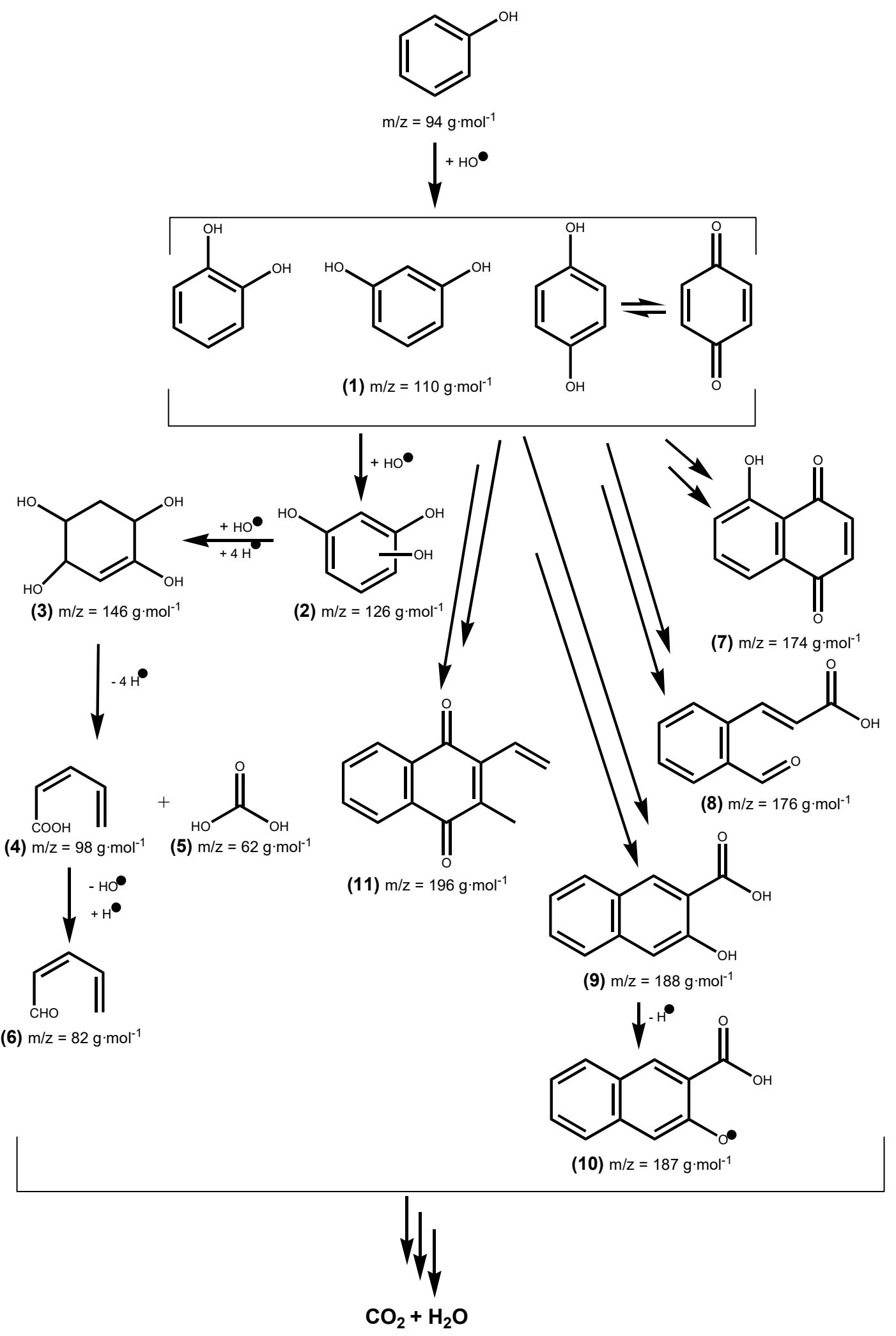

Figure 13. Proposed reaction pathways for the photocatalytic degradation of phenol over $\mathrm{M} / \mathrm{TiO}_{2}$ $(\mathrm{M}=\mathrm{Cu}, \mathrm{V}$, and $\mathrm{Cr})$ under $\mathrm{UV}$ and visible irradiation. $\mathrm{m} / \mathrm{z}$ ratios are rounded here, exact values are given in Table 5 . 


\section{Photodegradation and Energetic Efficiency of the Process}

Light scattering by the suspended catalyst particles and the characteristics of the surface contribute to reduce the photodegradation quantum yield $\left(\Phi_{\text {photodegradation }}\right)$ and the photonic efficiency of the

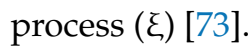

The photocatalysis quantum yield ( $\left.\Phi_{\text {Photocatalysis }}\right)$ is the ratio of moles of reactant consumed per Einstein absorbed by the photocatalyst [74]. It can be calculated as [75-77]:

$$
\Phi_{\text {photodegradation }}=\frac{k_{a p p}}{2.303 \cdot I_{\lambda} \cdot \varepsilon_{\lambda} \cdot l}
$$

where $\Phi_{\text {photodegradation }}$ is the photodegradation quantum yield, $\mathrm{k}_{\mathrm{app}}$ is the apparent pseudo first order rate constant, $I_{\lambda}$ (Einstein $\left.\cdot \mathrm{L}^{-1} \cdot \mathrm{s}^{-1}\right)$ is the light intensity at wavelength $\lambda, \varepsilon_{\lambda}\left(\mathrm{cm}^{-1} \cdot \mathrm{mol} \cdot \mathrm{dm}^{-3}\right)$ is the molar absorptivity at $\lambda$, and 1 is the path length of the photoreactor $(\mathrm{cm})$. The so-obtained $\Phi_{\text {photodegradation }}$ are shown in Table 6. Both for UV and UVA-Vis lamps, $\Phi_{\text {photodegradation }}(\mathrm{Cu})>\Phi_{\text {photodegradation }}(\mathrm{V})>$ $\Phi_{\text {photodegradation }}(\mathrm{Cr})$, with values higher than 1 for $\mathrm{Cu}$ and $\mathrm{V}$, pointing to the existence of secondary processes, that inflate the efficiency of the incident photons.

Table 6. Photodegradation quantum yields ( $\Phi$ photodegradation) and energy efficiency $\left(\mathrm{E}_{\mathrm{EO}}\right)$ for the photocatalyzed degradation of phenol over $(0.1 \% \mathrm{M}) / \mathrm{TiO}_{2}$ composites under Vis $\left(\lambda_{\mathrm{exc}}>366 \mathrm{~nm}\right)$ and $\mathrm{UV}\left(\lambda_{\text {exc }}=255 \mathrm{~nm}\right)$ irradiation. [Phenol $\left.] 0=50 \mathrm{mg} \cdot \mathrm{L}^{-1},[0.1 \% \mathrm{M}) / \mathrm{TiO}_{2}\right] 0=1.0 \mathrm{~g} \cdot \mathrm{L}^{-1}$, natural $\mathrm{pH}$, and $\mathrm{T}=298.0 \mathrm{~K}$.

\begin{tabular}{cccc}
\hline Lamp & $\mathbf{( 0 . 1} \mathbf{~} \mathbf{~ M}) / \mathbf{T i O}_{\mathbf{2}}$ & $\boldsymbol{\Phi}_{\text {photodegradation }}$ & $\mathbf{E}_{\text {EO }} / \mathbf{k W} \cdot \mathbf{L}^{\mathbf{- 1}} \cdot \mathbf{s}^{\mathbf{- 1}}$ \\
\hline \multirow{2}{*}{$\mathrm{UV}(254 \mathrm{~nm})$} & $\mathrm{Cu}$ & 1.17 & 6400 \\
& $\mathrm{~V}$ & 1.01 & 7385 \\
& $\mathrm{Cr}$ & 0.56 & 13395 \\
\hline \multirow{2}{*}{ UVA-Vis $\left(\lambda_{\text {exc }}>366 \mathrm{~nm}\right)$} & $\mathrm{Cu}$ & 2.81 & 37403 \\
& $\mathrm{~V}$ & 1.46 & 72000 \\
& $\mathrm{Cr}$ & 0.20 & 514286 \\
\hline
\end{tabular}

Photodegradation of organic micropollutants in aqueous solution is energy demanding, and an energy efficiency parameter $\left(\mathrm{E}_{\mathrm{EO}}\right)$ can be defined to analyse it, as the $\mathrm{kWh}$ of energy required to reduce the pollutant concentration per volume and time unit $\left(\mathrm{kW} \cdot \mathrm{L}^{-1} \cdot \mathrm{s}^{-1}\right)[78]$, expressed as:

$$
E_{E_{0}}=\frac{38.4 \cdot P}{V \cdot k_{a p p}}
$$

where $\mathrm{P}$ is the electric power consumed by the lamp $(\mathrm{kW}), \mathrm{V}$ is the volume $(\mathrm{L})$ of solution and $\mathrm{k}_{\text {app }}$ are the apparent photodegradation rate constants from Table 4. The values thus obtained for $\mathrm{E}_{\mathrm{EO}}$, compiled in Table 6, are lower with $254 \mathrm{~nm}$ than with $366 \mathrm{~nm}$, showing that $\mathrm{E}_{\mathrm{EO}}$ is far more favourable with UV lamps. The efficiency order varies, both for UV and UVA-Vis lamps, in the order $\mathrm{E}_{\mathrm{EO}}(\mathrm{Cu})<$ $\mathrm{E}_{\mathrm{EO}}(\mathrm{V})<\mathrm{E}_{\mathrm{EO}}(\mathrm{Cr})$.

\section{Conclusions}

The photocatalyzed degradation of phenol, as a model pollutant, in aqueous solution over titania-coated metal $(\mathrm{M}=\mathrm{Cu}, \mathrm{Cr}$, and $\mathrm{V})$ composites under visible $\left(\lambda_{\mathrm{exc}}>366 \mathrm{~nm}\right)$ and $\mathrm{UV}$ $\left(\lambda_{\text {exc }}=255 \mathrm{~nm}\right)$ irradiation is described. Metal surface impregnated photocatalyts were synthesized using the wet impregnation method and characterized by X-ray diffraction (XRD), X-ray fluorescence (XRF), UV-Vis diffuse reflectance spectroscopy (UV-Vis DRS), and surface area (BET). No oxides phases of the metal dopants were found. Analysis of XRD peak broadening, in terms of the uniform deformation model (UDM), points to the existence of tensile strain in $\mathrm{Cu}$-impregnated $\mathrm{TiO}_{2}-\mathrm{P} 25$, whereas compressive in $\mathrm{Cr}$ - and $\mathrm{V}$-impregnated $\mathrm{TiO}_{2}-\mathrm{P} 25$. 
UV-Vis DRS measurements clearly show the dependence of the band gap on the synthetic method. Raman spectra showed an enhancement of the crystallinity of the anatase phase by impregnation mainly with $\mathrm{Cu}$ and $\mathrm{V}$ cations. Red-shifts were also observed on the $\mathrm{E}_{\mathrm{g}}\left(140 \mathrm{~cm}^{-1}\right)$ peak $(\Delta$ Raman-shift $\left.=2.8-4.4 \mathrm{~cm}^{-1}\right)$ in $\mathrm{M}(0.1 \%) / \mathrm{TiO}_{2}$ samples, especially for $\mathrm{Cu}(0.1 \%) / \mathrm{TiO}_{2}$. Experimental evidences suggest at least a surface metal-linkage.

Type IV $\mathrm{N}_{2}$ adsorption-desorption isotherms were found, with a small H3 loop near the maximum relative pressure. $\mathrm{S}_{\mathrm{BET}}$ was similar for the three $\mathrm{M}(0.1 \%) / \mathrm{TiO}_{2}$ photocatalysts, ca. $45 \mathrm{~m}^{2} \cdot \mathrm{g}^{-1}$. Pore size distribution using BJH, D-H, and NLDFT models suggest those photocatalysts are mesoporous with a narrow pore distribution centered at ca. $25 \AA$, which is in agreement with the rest of textural data. PSDs using BJH and D-H models are fully coincident, and the same is observed using adsorption and desorption branches. Metal surface impregnated photocatalysts show similar surface roughness.

Their photocatalytic activity was followed by UV-Vis spectroscopy and HPLC-UV. A first-order equation was used to fit kinetic data. Similar results are obtained using UV-Vis spectroscopy and HPLC monitoring. Fastest phenol degradation was obtained with $\mathrm{M}(0.1 \%) / \mathrm{TiO}_{2}$ the order being $\mathrm{Cu}>\mathrm{V}>>\mathrm{Cr}>\mathrm{TiO}_{2} / \mathrm{P} 25$ under Vis radiation, whereas reactivity was $\mathrm{TiO}_{2} / \mathrm{P} 25>>\mathrm{Cu}>\mathrm{V}>\mathrm{Cr}$ under $\mathrm{UV}$ radiation.

The degree of mineralization was calculated in terms of TOC removal efficiency, and we were able to achieve more than $95 \%$ disappearance of the total organic carbon using visible light and less than $30 \%$ when treated with UV light.

Products and intermediate organic photoproducts were identified by HPLC-MS spectrometry, and the corresponding kinetic mechanism proposed.

Finally, the energetic efficiency of the process was analysed for $M(0.1 \%)$, showing that UV lamps are far superior to UVA lamps, and that the efficiency of the surface impregnated catalyst varies in the order $\mathrm{E}_{\mathrm{EO}}(\mathrm{Cu})<\mathrm{E}_{\mathrm{EO}}(\mathrm{V})<\mathrm{E}_{\mathrm{EO}}(\mathrm{Cr})$.

Supplementary Materials: The following are available online at http://www.mdpi.com/2079-4991/10/5/996/s1, Figure S1: SEM images of $(\mathrm{a}, \mathrm{d}) \mathrm{Cr}(0.1 \%) / \mathrm{TiO}_{2},(\mathrm{~b}, \mathrm{e}) \mathrm{Cu}(0.1 \%) / \mathrm{TiO}_{2}$ and $(\mathrm{c}, \mathrm{f}) \mathrm{V}(0.1 \%) / \mathrm{TiO}_{2}$, Figure $\mathrm{S} 2$ : Williamson-Hall plot for $\mathrm{Cu}(0.1 \%) / \mathrm{TiO}_{2}-\mathrm{P} 25$, anatase and rutile, Figure S3: Williamson-Hall plot for $\mathrm{Cr}(0.1 \%) / \mathrm{TiO}_{2}-\mathrm{P} 25$, anatase and rutile, Figure S4: Williamson-Hall plot for $\mathrm{V}(0.1 \%) / \mathrm{TiO}_{2}-\mathrm{P} 25$, anatase and rutile, Figure S5: Size-Strain plot for $\mathrm{Cu}(0.1 \%) / \mathrm{TiO}_{2}-\mathrm{P} 25$, anatase and rutile, Figure S6: Size-Strain plot for $\mathrm{Cr}(0.1 \%) / \mathrm{TiO}_{2}-\mathrm{P} 25$, anatase and rutile, Figure S7: Size-Strain plot for $\mathrm{V}(0.1 \%) / \mathrm{TiO}_{2}-\mathrm{P} 25$, anatase and rutile, Figure S8: $\mathrm{N} 2$ adsorption-desorption isotherm of $\mathrm{V}(0.1 \%) / \mathrm{TiO}_{2}-\mathrm{P} 25$ photocatalyst, Figure S9: N2 adsorption-desorption isotherm of $\mathrm{Cr}(0.1 \%) / \mathrm{TiO}_{2}-\mathrm{P} 25$ photocatalyst, Figure S10: Differential specific pore volume vs. pore width distribution for $\mathrm{Cu}(0.1 \%) / \mathrm{TiO}_{2}-\mathrm{P} 25$ photocatalyst using the $\mathrm{BJH}$ model. Inset: using the D-H model, Figure S11: Comparison between observed and calculated isotherm of $\mathrm{Cu}(0.1 \%) / \mathrm{TiO}_{2}-\mathrm{P} 25$ photocatalyst, Figure S12: Frenkel-Halsey-Hill fractal analysis of the $\mathrm{Cu}(0.1 \%) / \mathrm{TiO}_{2}-\mathrm{P} 25$ isotherm, Figure S13: Frenkel-Halsey-Hill fractal analysis of the $\mathrm{Cr}(0.1 \%) / \mathrm{TiO}_{2}-\mathrm{P} 25$ isotherm, Figure S14: Frenkel-Halsey-Hill fractal analysis of the $\mathrm{V}(0.1 \%) / \mathrm{TiO}_{2}-\mathrm{P} 25$ isotherm, Figure S15: Photodegradation of phenol over $\mathrm{Cu}(\mathrm{X} \%) / \mathrm{TiO}_{2}$ under NUV-Vis irradiation, Figure S16: Photodegradation of phenol over $\mathrm{Cu}(\mathrm{X} \%) / \mathrm{TiO}_{2}$ under UV irradiation, Figure S17: Photodegradation of phenol over $\mathrm{V}(\mathrm{X} \%) / \mathrm{TiO}_{2}$ under NUV-Vis irradiation, Figure S18: Photodegradation of phenol over $\mathrm{V}(\mathrm{X} \%) / \mathrm{TiO}_{2}$ under NUV-Vis irradiation, Figure S19: Photodegradation of phenol over $\mathrm{V}(\mathrm{X} \%) / \mathrm{TiO}_{2}$ under UV irradiation, Figure S20: Photodegradation of phenol over $\mathrm{V}(\mathrm{X} \%) / \mathrm{TiO}_{2}$ under UV irradiation, Figure S21: Photodegradation of phenol over $\mathrm{Cr}(\mathrm{X} \%) / \mathrm{TiO}_{2}$ under NUV-Vis irradiation, Figure S22: Photodegradation of phenol over $\mathrm{Cr}(\mathrm{X} \%) / \mathrm{TiO} 2$ under NUV-Vis irradiation, Figure S23: Photodegradation of phenol over $\mathrm{Cr}(\mathrm{X} \%) / \mathrm{TiO}_{2}$ under UV irradiation, Figure S24: Photodegradation of phenol over $\mathrm{Cr}(\mathrm{X} \%) / \mathrm{TiO}_{2}$ under UV irradiation, Table S1: Scherrer crystallite size, anatase mass fraction, main diffraction peaks and indexation for $\mathrm{XRD}$ of $0.1 \% \mathrm{Cu}, \mathrm{Cr}$ and $\mathrm{V}$ doped $\mathrm{TiO}_{2}-\mathrm{P} 25$ photocatalysts before and after $2 \mathrm{~h}$ suspension in water.

Author Contributions: Conceptualization, M.E.H. and M.C.; methodology, M.E.A.,L.R.-L., J.A.S., M.C.; software, J.A.S.; validation, A.E.H., L.R.-L, J.A.S., M.C.; formal analysis, S.B., L.R.-L., J.A.S., MC.; investigation, S.B., L.R.-L, J.A.S., M.C.; resources, J.A.S., M.C.; data curation, S.B., L.R.-L.; writing—original draft preparation, S.B., L.R.-L., M.C.; writing—review and editing, J.A.S., M.C.; visualization, J.A.S., M.C.; supervision, M.E.A., M.C.; project administration, J.A.S., M.C.; funding acquisition, M.E.A., J.A.S., M.C. All authors have read and agreed to the published version of the manuscript.

Funding: This research was partially supported by the Group of Chemical Reactivity \& Photoreactivity at University and funded by the Spanish Ministerio de Economía y Competitividad through project CTQ2015-71238-R (MINECO/FEDER), and the regional government Xunta de Galicia (Project Grupo Potencial Crecemento (GPC) ED431B 2017/59), respectively. 
Acknowledgments: S.B. would like to thank the Ministry of Education of Morocco for a PhD grant to develop her $\mathrm{PhD}$ Thesis.

Conflicts of Interest: The authors declare no conflict of interest.

\section{References}

1. Teh, C.M.; Mohamed, A.R. Roles of titanium dioxide and ion-doped titanium dioxide on photocatalytic degradation of organic pollutants (phenolic compounds and dyes) in aqueous solutions: A review. J. Alloys Compd. 2011, 509, 1648-1660. [CrossRef]

2. Blanco, E.; Casais, M.C.; Mejuto, M.C.; Cela, R. Capillary Electrophoresis|Phenols; Wilson, I.D., Ed.; Elsevier: Amsterdam, The Netherlands, 2000; pp. 1-9.

3. Chimentão, R.J.; Medina, F.; Fierro, J.L.G.; Llorca, J.; Sueiras, J.E.; Cesteros, Y.; Salagre, P. Propene epoxidation by nitrous oxide over $\mathrm{Au}-\mathrm{Cu} / \mathrm{TiO}_{2}$ alloy catalysts. J. Mol. Catal. A Chem. 2007, 274, 159-168. [CrossRef]

4. Fath, B.D. Encyclopedia of Ecology; Elsevier: Amsterdam, The Netherlands, 2008; pp. 2682-2689.

5. Wang, F.; Hu, Y.; Guo, C.; Huang, W.; Liu, C. Enhanced phenol degradation in coking wastewater by immobilized laccase on magnetic mesoporous silica nanoparticles in a magnetically stabilized fluidized bed. Bioresour. Technol. 2012, 110, 120-124. [CrossRef] [PubMed]

6. Canle, L.M.; Santaballa, J.A.; Vulliet, E. On the mechanism of $\mathrm{TiO}_{2}$-photocatalyzed degradation of aniline derivatives. J. Photochem. Photobiol. A Chem. 2005, 175, 192-200. [CrossRef]

7. Zhang, L.; Jaroniec, M. Toward designing semiconductor-semiconductor heterojunctions for photocatalytic applications. Appl. Surf. Sci. 2018, 430, 2-17. [CrossRef]

8. Zheng, Y.; Pan, Z.; Wang, X. Advances in photocatalysis in China. Chin. J. Catal. 2013, 34, 524-535. [CrossRef]

9. Helali, S. Application de la Photocatalyse Pour la Dégradation des Polluants Chimiques et Bactériologiques Dans L'eau en Utilisant des Catalyseurs Irradiés Par des Photons de Lumière Naturelle ou Artificielle (UV-A/UV-B). Ph.D. Thesis, Claude Bernard-Lyon I, Villeurbanne, France, 17 December 2012.

10. Kouamé, N.A.; Alaoui, O.T.; Herissan, A.; Larios, E.; José-Yacaman, M.; Etcheberry, A.; Colbeau-Justin, C.; Remita, H. Visible light-induced photocatalytic activity of modified titanium(iv) oxide with zero-valent bismuth clusters. New J. Chem. 2015, 39, 2316-2322. [CrossRef]

11. Khaki, M.R.D.; Shafeeyan, M.S.; Raman, A.A.A.; Daud, W.M.A. Application of doped photocatalysts for organic pollutant degradation-A review. J. Environ. Manag. 2017, 198, 78-94. [CrossRef]

12. Zhang, J.; Xu, Q.; Feng, Z.; Li, M.; Li, C. Importance of the relationship between surface phases and photocatalytic activity of TiO. Angew. Chem. 2008, 47, 1766-1769. [CrossRef]

13. Dobrosz-Gómez, I.; Gómez-García, M.Á.; López, Z.S.M.; GilPavas, E.; Bojarska, J.; Kozanecki, M.; Rynkowski, J.M. Transition metal loaded $\mathrm{TiO}_{2}$ for phenol photo-degradation. C. R. Chim. 2015, 18, 1170-1182. [CrossRef]

14. Ata, R.; Sacco, O.; Vaiano, V.; Rizzo, L.; Tore, G.Y.; Sannino, D. Visible light active N-doped TiO 2 immobilized on polystyrene as efficient system for wastewater treatment. J. Photochem. Photobiol. A Chem. 2017, 348, 255-262. [CrossRef]

15. Konstantinou, I.K.; Albanis, T.A. $\mathrm{TiO}_{2}$-assisted photocatalytic degradation of azo dyes in aqueous solution: Kinetic and mechanistic investigations: A review. Appl. Catal. B Environ. 2004, 49, 1-14. [CrossRef]

16. Spurr, R.A.; Myers, H. Quantitative analysis of anatase-rutile mixtures with an X-ray diffractometer. Anal. Chem. 1957, 29, 760-762. [CrossRef]

17. Scherrer, P. Bestimmung der grosse und der inneren struktur von kolloidteilchen mittels rontgenstrahlen. Math.-Phys. Kl. 1918, 2, 98-100.

18. Williamson, G.K.; Hall, W.H. X-ray line broadening from filed aluminium and wolfram. ACTA Metall. 1953, 1, 22-31. [CrossRef]

19. Nye, J.F. Physical Properties of Crystals; Clarendon Press: Oxford, UK, 2008.

20. Halsey, G. Physical adsorption on non-uniform surfaces. J. Chem. Phys. 1948, 16, 931-937. [CrossRef]

21. Frenkel, J.I. Kinetic Theory of Liquids; Clarendon Press: Oxford, UK, 1946.

22. Hill, T.L. Advances in Catalysis. In Theory of Physical Adsorption; Elsevier Science \& Technology: Amsterdam, The Netherlands, 1952; Volume 4, pp. 211-258.

23. López, R.; Gómez, R.; Oros-Ruiz, S. Photophysical and photocatalytic properties of $\mathrm{TiO}_{2}$-Cr sol-gel prepared semiconductors. Catal. Today 2011, 166, 159-165. [CrossRef] 
24. Kuhn, B.J.; Braslavsky, S.E.; Schmidt, R. Chemical actinometry (IUPAC Technical Report). Pure Appl. Chem. 2004, 76, 2105-2146. [CrossRef]

25. Boukhatem, H.; Khalaf, H.; Djouadi, L.; González, F.V.; Navarro, R.M.; Santaballa, J.A.; Canle, M. Photocatalytic activity of mont-La (6\%)- $\mathrm{Cu}_{0.6} \mathrm{Cd}_{0.4} \mathrm{~S}$ catalyst for phenol degradation under near UV Visible light irradiation. Appl. Catal. B Environ. 2017, 211, 114-125. [CrossRef]

26. Carp, O.; Huisman, C.L.; Reller, A. Photoinduced reactivity of titanium dioxide. Prog. Solid State Chem. 2004, 32, 33-177. [CrossRef]

27. Zhang, Z.; Wang, C.; Zakaria, R.; Ying, J.Y. Role of particle size in nanocrystalline $\mathrm{TiO}_{2}$-Based photocatalysts. J. Phys. Chem. B 1998, 102, 10871-10878. [CrossRef]

28. Jiang, X.; Manawan, M.; Feng, T.; Qian, R.; Zhao, T.; Zhou, G.; Kong, F.; Wang, Q.; Dai, S.; Pan, J.H. Anatase and rutile in evonik aeroxide P25: Heterojunctioned or individual nanoparticles? Catal. Today 2018, 300, 12-17. [CrossRef]

29. Zhang, W.; Li, Y.; Zhu, S.; Wang, F. Copper doping in titanium oxide catalyst film prepared by dc reactive magnetron sputtering. Catal. Today 2004, 93, 589-594. [CrossRef]

30. Chiang, K.; Amal, R.; Tran, T. Photocatalytic degradation of cyanide using titanium dioxide modified with copper oxide. Adv. Environ. Res. 2002, 6, 471-485. [CrossRef]

31. Doong, R.; Chang, P.; Huang, C. Microstructural and photocatalytic properties of sol-gel-derived vanadium-doped mesoporous titanium dioxide nanoparticles. J. Non-Cryst. Solids 2009, 355, 2302-2308. [CrossRef]

32. Tian, B.; Li, C.; Gu, F.; Jiang, H.; Hu, Y.; Zhang, J. Flame sprayed V-doped $\mathrm{TiO}_{2}$ nanoparticles with enhanced photocatalytic activity under visible light irradiation. Chem. Eng. J. 2009, 151, 220-227. [CrossRef]

33. Wang, L.; Egerton, T.A. The influence of chromium on photocatalysis of propan-2-ol and octadecanoic acid oxidation by rutile TiO. J. Photochem. Photobiol. A Chem. 2013, 252, 211-215. [CrossRef]

34. Devi, L.G.; Murthy, B.N.; Kumar, S.G. Photocatalytic activity of $\mathrm{TiO}_{2}$ doped with $\mathrm{Zn} 2+$ and V5+ transition metal ions: Influence of crystallite size and dopant electronic configuration on photocatalytic activity. Mater. Sci. Eng. B 2010, 166, 1-6. [CrossRef]

35. Devi, L.G.; Kumar, S.G. Influence of physicochemical-electronic properties of transition metal ion doped polycrystalline titania on the photocatalytic degradation of Indigo Carmine and 4-nitrophenol under UV/solar light. Appl. Surf. Sci. 2011, 257, 2779-2790. [CrossRef]

36. Ahlawat, A.; Sathe, V.G.; Reddy, V.R.; Gupta, A. Mossbauer, Raman and X-ray diffraction studies of superparamagnetic NiFe2O4 nanoparticles prepared by sol-gel auto-combustion method. J. Magn. Magn. Mater. 2011, 323, 2049-2054. [CrossRef]

37. Frank, O.; Zukalova, M.; Laskova, B.; Kürti, J.; Koltai, J.; Kavan, L. Raman spectra of titanium dioxide (anatase, rutile) with identified oxygen isotopes $(16,17,18)$. Phys. Chem. Chem. Phys.: PCCP 2012, 14, 14567-14572. [CrossRef]

38. Abdulrazzak, F.H.; Hussein, F.H. Effects of nanoparticle size on catalytic and photocatalytic activity of carbon nanotubes-titanium dioxide composites. J. Environ. Anal. Chem. 2015, 2, 2. [CrossRef]

39. Mougin, J.; Le Bihan, T.; Lucazeau, G. High-pressure study of Cr2O3 obtained by high-temperature oxidation by X-ray diffraction and Raman spectroscopy. J. Phys. Chem. Solids 2001, 62, 553-563. [CrossRef]

40. Navas, J.; Sánchez-Coronilla, A.; Aguilar, T.; Hernández, N.C.; de los Santos, D.M.; Sánchez-Márquez, J.; Zorrilla, D.; Fernández-Lorenzo, C.; Alcántara, R.; Martín-Calleja, J. Experimental and theoretical study of the electronic properties of Cu-doped anatase TiO. Phys. Chem. Chem. Phys.: PCCP 2014, 16, 3835-3845. [CrossRef] [PubMed]

41. Ramana, C.V.; Smith, R.J.; Hussain, O.M.; Massot, M.; Julien, C.M. Surface analysis of pulsed laser-deposited V2O5 thin films and their lithium intercalated products studied by Raman spectroscopy. Surf. Interface Anal. 2005, 37, 406-411. [CrossRef]

42. Bhattacharyya, K.; Varma, S.; Tripathi, A.K.; Bharadwaj, S.R.; Tyagi, A.K. Effect of vanadia doping and its oxidation state on the photocatalytic activity of $\mathrm{TiO}_{2}$ for gas-phase oxidation of ethene. J. Phys. Chem. C 2008, 112, 19102-19112. [CrossRef]

43. Sahoo, S.; Arora, A.K.; Sridharan, V. Raman line shapes of optical phonons of different symmetries in anatase $\mathrm{TiO}_{2}$ nanocrystals. J. Phys. Chem. C 2009, 113, 16927-16933. [CrossRef] 
44. Zhang, Y.; Harris, C.X.; Wallenmeyer, P.; Murowchick, J.; Chen, X. Asymmetric lattice vibrational characteristics of rutile $\mathrm{TiO}_{2}$ as revealed by laser power dependent raman spectroscopy. J. Phys. Chem. C 2013, 117, 24015-24022. [CrossRef]

45. Colón, G.; Maicu, M.; Hidalgo, M.C.; Navío, J.A. Cu-doped $\mathrm{TiO}_{2}$ systems with improved photocatalytic activity. Appl. Catal. B Environ. 2006, 67, 41-51. [CrossRef]

46. Binas, V.; Venieri, D.; Kotzias, D.; Kiriakidis, G. Modified $\mathrm{TiO}_{2}$ based photocatalysts for improved air and health quality. J. Mater. 2017, 3, 3-16.

47. Choi, W.; Termin, A.; Hoffmann, M.R. The role of metal ion dopants in quantum-sized $\mathrm{TiO}_{2}$ : Correlation between photoreactivity and charge carrier recombination dynamics. J. Phys. Chem. 1994, 98, 13669-13679. [CrossRef]

48. Tauc, J.; Grigorovici, R.; Vancu, A. Optical Properties and Electronic Structure of Amorphous Germanium. Phys. Status Solidi B 1966, 15, 627-637. [CrossRef]

49. Coulter, J.B.; Dunbar, P.B. Assessing Tauc Plot Slope Quantification: ZnO Thin Films as a Model System. Phys. Status Solidi B 2018, 255, 1700393. [CrossRef]

50. Khairy, M.; Zakaria, W. Effect of metal-doping of $\mathrm{TiO}_{2}$ nanoparticles on their photocatalytic activities toward removal of organic dyes. Egypt. J. Pet. 2014, 23, 419-426. [CrossRef]

51. Kamble, R.; Mahajan, S.; Puri, V.; Shinde, H.; Garadkar, K. Visible light-driven high photocatalytic activity of $\mathrm{Cu}$-doped $\mathrm{TiO}_{2}$ nanoparticles synthesized by hydrothermal method. Mater. Sci. Res. India 2018, 15, 197-208. [CrossRef]

52. Pestryakov, A.N.; Petranovskii, V.P.; Kryazhov, A.; Ozhereliev, O.; Pfänder, N.; Knop-Gericke, A. Study of copper nanoparticles formation on supports of different nature by UV-Vis diffuse reflectance spectroscopy. Chem. Phys. Lett. 2004, 385, 173-176. [CrossRef]

53. Qiu, X.; Miyauchi, M.; Sunada, K.; Minoshima, M.; Liu, M.; Lu, Y.; Li, D.; Shimodaira, Y.; Hosogi, Y.; Kuroda, Y.; et al. Hybrid $\mathrm{Cu}(\mathrm{x}) \mathrm{O} / \mathrm{TiO}_{2}$ nanocomposites as risk-reduction materials in indoor environments. ACS Nano 2012, 6, 1609-1618. [CrossRef]

54. Irie, H.; Kamiya, K.; Shibanuma, T.; Miura, S.; Tryk, D.A.; Yokoyama, T.; Hashimoto, K. Visible light-sensitive $\mathrm{Cu}(\mathrm{II})$-grafted $\mathrm{TiO}_{2}$ photocatalysts: Activities and X-ray absorption fine structure analyses. J. Phys. Chem. C 2009, 113, 10761-10766. [CrossRef]

55. Liu, L.; Li, Y. Understanding the reaction mechanism of photocatalytic reduction of $\mathrm{CO} 2$ with $\mathrm{H} 2 \mathrm{O}$ on $\mathrm{TiO}_{2}$-based photocatalysts: A review. Aerosol Air Qual. Res. 2014, 14, 453-469. [CrossRef]

56. Yoong, L.S.; Chong, F.K.; Dutta, B.K. Development of copper-doped $\mathrm{TiO}_{2}$ photocatalyst for hydrogen production under visible light. Energy 2009, 34, 1652-1661. [CrossRef]

57. Shafei, A.; Sheibani, S. Visible light photocatalytic activity of $\mathrm{Cu}$ doped $\mathrm{TiO}_{2}-\mathrm{CNT}$ nanocomposite powder prepared by sol-gel method. Mater. Res. Bull. 2019, 110, 198-206. [CrossRef]

58. Dvoranová, D.; Brezová, V.; Mazúr, M.; Malati, M.A. Investigations of metal-doped titanium dioxide photocatalysts. Appl. Catal. B Environ. 2002, 37, 91-105. [CrossRef]

59. Jaimy, K.B.; Ghosh, S.; Sankar, S.; Warrier, K.G.K. An aqueous sol-gel synthesis of chromium(III) doped mesoporous titanium dioxide for visible light photocatalysis. Mater. Res. Bull. 2011, 46, 914-921. [CrossRef]

60. Yan, H.; Wang, X.; Yao, M.; Yao, X. Band structure design of semiconductors for enhanced photocatalytic activity: The case of TiO. Prog. Nat. Sci. Mater. Int. 2013, 23, 402-407. [CrossRef]

61. Thommes, M.; Kaneko, K.; Neimark, A.V.; Olivier, J.P.; Rodriguez-Reinoso, F.; Rouquerol, J.; Sing, K.S.W. Physisorption of gases, with special reference to the evaluation of surface area and pore size distribution (IUPAC Technical Report). Pure Appl. Chem. 2015, 87, 1051-1069. [CrossRef]

62. Barrett, E.P.; Joyner, L.G.; Halenda, P.P. The determination of pore volume and area distributions in porous substances. I. Computations from nitrogen isotherms. J. Am. Chem. Soc. 1951, 73, 373-380. [CrossRef]

63. Lastoskie, C.M.; Quirke, N.; Gubbins, K.E. Chapter Structure of porous adsorbents: Analysis using density functional theory and molecular simulation. Stud. Surf. Sci. Catal. 1997, 104, 745-775.

64. Yang, X.; Wang, X.; Wang, S.; Sun, H.; Lian, J. Preparation and photocatalytic performance of Cu-doped $\mathrm{TiO}_{2}$ nanoparticles. Trans. Nonferrous Met. Soc. China 2015, 25, 504-509. [CrossRef]

65. Fox, M.A.; Dulay, M.T. Heterogeneous photocatalysis. Chem. Rev. 1993, 1, 341-357. [CrossRef]

66. Palmisano, L.; Augugliaro, V.; Sclafani, A.; Schiavello, M. Activity of chromium-ion-doped titania for the dinitrogen photoreduction to ammonia and for the phenol photodegradation. J. Phys. Chem. 1988, 92, 6710-6713. [CrossRef] 
67. Romeiro, A.; Azenha, M.E.; Canle, M.; Rodrigues, V.H.N.; Da Silva, J.P.; Burrows, H.D. Titanium dioxide nanoparticle photocatalysed degradation of ibuprofen and naproxen in water: Competing hydroxyl radical attack and oxidative decarboxylation by semiconductor holes. ChemSelect 2018, 3, 10915-10924. [CrossRef]

68. Maruska, H.P.; Ghosh, A.K. Transition-metal dopants for extending the response of titanate photoelectrolysis anodes. Sol. Energy Mater. 1979, 1, 237-247. [CrossRef]

69. Schaub, R.; Thostrup, P.; López, N.A.; Laegsgaard, E.; Stengsgaard, I.; Nørskov, J.K.; Besenbacher, F. Oxygen vacancies as active sites for water dissociation on rutile $\mathrm{TiO}_{2}(110)$. Phys. Rev. Lett. 2001, 87, 266104. [CrossRef] [PubMed]

70. Lv, K.; Guo, X.; Wu, X.; Li, M.; Li, Q.; Ho, W.; Ye, H.; Du, D. Photocatalytic selective oxidation of phenol to produce dihydroxybenzenes in a $\mathrm{TiO}_{2} / \mathrm{UV}$ system: Hydroxyl radical versus hole. Appl. Catal. B Environ. 2016, 199, 405-411. [CrossRef]

71. Turki, A.; Guillard, C.; Dappozze, F.; Ksibi, Z.; Berhault, G.; Kochkar, H. Phenol photocatalytic degradation over anisotropic $\mathrm{TiO}_{2}$ nanomaterials: Kinetic study, adsorption isotherms and formal mechanisms. Appl. Catal. B Environ. 2015, 163, 404-414. [CrossRef]

72. Diak, M.; Klein, M.; Klimczuk, T.; Lisowski, W.; Remita, H.; Zaleska-Medynska, A.; Grabowska, E. Photoactivity of decahedral $\mathrm{TiO}_{2}$ loaded with bimetallic nanoparticles: Degradation pathway of phenol-1-13C and hydroxyl radical formation. Appl. Catal. B Environ. 2017, 200, 56-71. [CrossRef]

73. Serpone, N. Relative photonic efficiencies and quantum yields in heterogeneous photocatalysis. J. PhotoChem. Photobiol. A Chem. 1997, 104, 1-12. [CrossRef]

74. Serpone, N.; Salinaro, A. Terminology, relative photonic efficiencies and quantum yields in heterogeneous photocatalysis. Part I: Suggested protocol. Pure Appl. Chem. 1999, 71, 303-320. [CrossRef]

75. Wong, C.C.; Chu, W. The direct photolysis and photocatalytic degradation of alachlor at different $\mathrm{TiO}_{2}$ and UV sources. Chemosphere 2003, 50, 981-987. [CrossRef]

76. Chu, W.; Jafvert, C.T.; Diehl, C.A.; Marley, K.; Larson, R.A. Phototransformations of polychlorobiphenyls in Brij 58 micellar solutions. Environ. Sci. Technol. 1998, 32, 1989-1993. [CrossRef]

77. Chu, W.; Jafvert, C.T. Photodechlorination of polychlorobenzene congeners in surfactant micelle solutio-ns. Environ. Sci. Technol. 1994, 28, 2415-2422. [CrossRef] [PubMed]

78. Bolton, J.R.; Bircher, K.G.; Tumas, W.; Tolman, C.A. Figures-of-merit for the technical development and application of advanced oxidation technologies for both electric and solar-driven systems. Pure Appl. Chem. 2001, 73, 627-637. [CrossRef]

(C) 2020 by the authors. Licensee MDPI, Basel, Switzerland. This article is an open access article distributed under the terms and conditions of the Creative Commons Attribution (CC BY) license (http://creativecommons.org/licenses/by/4.0/). 